\title{
基于分子内三中心氢键的超分子组装体系及其应用
}

\author{
裴强* 丁爱祥吴晋晋 \\ (信阳师范学院化学化工学院 河南信阳 464000)
}

\begin{abstract}
摘要 分子内三中心氢键被视为是一种高效且可靠地控制分子构象的手段, 可以诱导线性分子形成特定构象(折叠、螺 旋、扩展及 “之” 字形等). 根据氢键结合原子的种类，系统地综述了基于 $\mathrm{O} \cdots \mathrm{H} \cdots \mathrm{O}$ 型、 $\mathrm{S} \cdots \mathrm{H} \cdots \mathrm{X}(\mathrm{X}=\mathrm{N}, \mathrm{O})$ 型、 $\cdots$ $\mathrm{H} \cdots \mathrm{X}(\mathrm{X}=\mathrm{N}, \mathrm{O})$ 型、 $\mathrm{F} \cdots \mathrm{H} \cdots \mathrm{X}(\mathrm{X}=\mathrm{F}, \mathrm{O}, \mathrm{N})$ 型分子内三中心氢键的超分子组装体系的研究进展, 重点介绍了大环化合 物、折叠体与含孔螺旋化合物、分子拉链等超分子组装体的合成以及它们在促进有机反应、分子识别、跨膜通道、分 子机器、软物质材料等领域的应用. 希望为此类超分子组装体的合成及应用提供有益参考.

关键词 分子内三中心氢键；超分子自组装；结构设计；构象控制；应用
\end{abstract}

\section{Supramolecular Assemblies Based on Intramolecular Three-Center Hydrogen Bond and their Applications}

\author{
Pei, Qiang* Ding, Aixiang Wu, Jinjin \\ (College of Chemistry and Chemical Engineering, Xinyang Normal University, Xinyang, Henan 464000)
}

\begin{abstract}
The intramolecular three-center hydrogen bond is regarded as an efficient and reliable means to control molecular conformation, which can induce linear molecules to form specific conformations (folding, helix, expansion, zigzag, etc.). In this paper, the research progress on supramolecular assemblies based on different types of intramolecular three-center hydrogen bond is summarized in detail according to the kinds of hydrogen bonding atoms, such as $\mathrm{O} \cdots \mathrm{H} \cdots \mathrm{O}, \mathrm{S} \cdots \mathrm{H} \cdots \mathrm{X}(\mathrm{X}=$ $\mathrm{N}, \mathrm{O}), \mathrm{N} \cdots \mathrm{H} \cdots \mathrm{X}(\mathrm{X}=\mathrm{N}, \mathrm{O}), \mathrm{F} \cdots \mathrm{H} \cdots \mathrm{X}(\mathrm{X}=\mathrm{F}, \mathrm{O}, \mathrm{N})$, and so on. More specifically, the synthesis of supramolecular assemblies is elaborated, including macrocyclic compounds, foldamers, porous helical compounds and molecular duplexes. Furthermore, their applications in promoting organic reactions, molecular recognition, transmembrane channels, molecular machines, soft materials are introduced. It is anticipated that this review can provide a useful reference for the synthesis and applications of the three-center hydrogel bond-based supramolecular assemblies.
\end{abstract}

Keywords intramolecular three-center hydrogen bond; supramolecular self-assembly; structure design; conformation control; application

氢键(Hydrogen Bonding)是指与电负性极强的原子 $\mathrm{X}($ 如 $\mathrm{F}, \mathrm{O}, \mathrm{N})$ 相结合的氢原子和另一分子中电负性极强 的原子 $\mathrm{Y}($ 如 $\mathrm{F}, \mathrm{O}, \mathrm{N})$ 之间形成的一种弱键, 可以表示成 $\mathrm{X}-\mathrm{H} \cdots \mathrm{Y}$. 其中, $\mathrm{H}$ 原子称为氢键给体, 而含有孤对电 子的 $\mathrm{Y}$ 原子称为氢键受体 ${ }^{[1]}$. 氢键强度适中, 具有方向 性、饱和性以及动态可逆性, 是自然界中最基本的分子 间弱相互作用力之一，被广泛应用于超分子自组装领 域 ${ }^{[2]}$. 此外, 氢键的结合方式丰富 ${ }^{[3-4]}$. 根据组成氢键的 氢键给体和氢键受体数目之和, 可以分为两中心氢键 (1)、三中心氢键(2 和 3)以及四中心氢键(4)等(图 1). 其
中, 三中心氢键最初被称为 “分叉型” (Bifurcated)氢键, 存在 2 种不同形式, 即 $X H Y$ 型 $(H$ 为氢键给体, $X / Y$ 为氢 键受体, 2) 和 $\mathrm{HXH}$ 型 ( $\mathrm{H}$ 为氢键给体, $\mathrm{X}$ 为氢键受体, 3 ). 后来, Maluszynska ${ }^{[5]}$ 和 Taylor 等 ${ }^{[6]}$ 建议将 XHY 型氢键称 作三中心氢键. 事实上, 早在 1939 年 Albrecht 等 ${ }^{[7]}$ 就发 现在 $\alpha$-氨基乙酸晶体中存在上述定义的氢键. 直到 20 世纪 80 年代, 因在更多小分子和生物大分子的固态结 构中发现这种氢键, 人们才逐渐接受和重视三中心氢键 概念 ${ }^{[8]}$.

\footnotetext{
* Corresponding author. E-mail: peiqiangxynu@163.com

Received May 20, 2020; revised July 6, 2020; published online August 18, 2020.

Project supported by the Doctoral Scientific Research Startup Foundation of Xinyang Normal University (Nos. 18077, 18072), and the Key Scientific Research Project of Henan Provincial Higher Educational Institutions (No. 19A150042).

信阳师范学院学院博士科研启动基金(Nos. 18077, 18072)、河南省高等学校重点科学研究(No. 19A150042)资助项目.
} 
<smiles>[Y]C(N)OC([Y])O[CH]N</smiles><smiles>C1C2OOC12</smiles><smiles>[Y][X]([Y])(N)OC=C</smiles>

图 1 氢键结合方式: 两中心氢键 $(1)$, 三中心氢键 $(2$ 和 3$)$ 和四 中心氢键(4)

Figure 1 Bonding patterns of hydrogen bond: two-center hydrogen bond (1), three-center hydrogen bond ( 2 and 3 ), and fourcenter hydrogen bond (4)

根据氢键形成的位置, 三中心氢键可分为分子间三 中心氢键和分子内三中心氢键. 分子内三中心氢键是一 种高效且可靠地控制分子构象的手段, 可以诱导线型分 子形成特定构象，例如折叠、螺旋、扩展及 “之” 字形 等构象 ${ }^{[9]}$. 在过去的二三十年中, 分子内三中心氢键的 研究取得了很大进展. 基于分子内三中心氢键, 研究人 员构建了各种各样结构美妙、功能丰富的超分子组装体

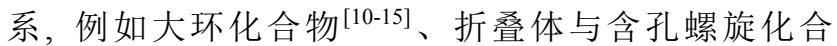
物 ${ }^{[16-18]}$ 、分子拉链 ${ }^{[19]}$. 本文将对基于分子内三中心氢键 的超分子组装体系的研究进展进行综述, 重点介绍大环 化合物、折叠体与含孔螺旋化合物、分子拉链等超分子 组装体系的设计和自组装行为, 以及它们在促进有机反 应、分子识别、跨膜通道、分子机器、软物质材料等领 域的应用, 希望为该领域今后的研究工作提供有益参 考.

\section{1 分子内三中心氢键}

分子内三中心氢键是由同一个分子的不同部位之 间相互作用形成，一般形成五元或六元环状结构，能够 有效限制相关共价键的自由转动, 从而减少构象转变的 机会, 可以对分子的构象进行预组织. 早在 2000 年, 龚 兵等 ${ }^{[20]}$ 设计在间位或对位被硝基或羧基修饰的芳香胺 和芳香酸的特定位置引入醚链, 通过还原、水解以及缩 合反应形成芳香低聚酰胺. 芳香低聚酰胺的醚链上的氧 原子可作为氢键的受体, 与酰胺氢原子在骨架的外侧分 别形成 $\mathrm{S}(5)$ 型和 $\mathrm{S}(6)$ 型氢键, 这两种类型氢键共同组成 了分子内三中心氢键 (5, 图 2). 同时, 结构中的醚链可 以改善芳香低聚酰胺在有机溶剂中的溶解性.

通过量子化学从头计算法( $a b$ initio 分子轨道法)对 酰胺 5 及其异构体 5a 5 (图 2)的计算研究结果显示, 含分子内三中心氢键的酰胺 $\mathbf{5}$ 的相对能量更低, 更倾向 于形成平面构象. 此外, 核磁测试结果显示酰胺 5 中存 在着明显的正协同效应(positive cooperativity), 即组成 分子内三中心氢键的 2 个两中心氢键之间存在相互作 用，导致整个氢键体系强度增加. 与不含分子内三中心 氢键的酰胺(6 和 7)对比, 通过 ${ }^{1} \mathrm{H}$ NMR 观察到酰胺 5 中 氢的化学位移在氯仿中明显向低场移动, 且不受浓度影 (a)

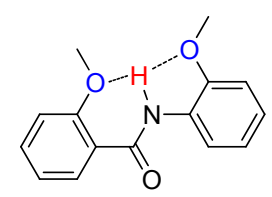

$5(0 \mathrm{kal} / \mathrm{mol})$

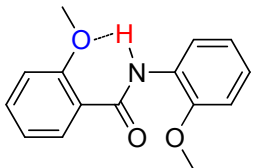

5b $(14.51 \mathrm{kal} / \mathrm{mol})$

(b)

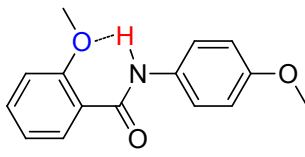

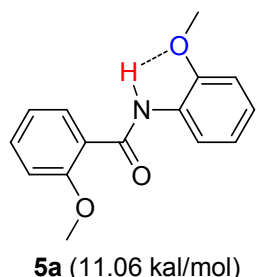

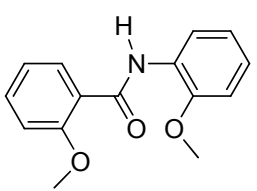

$5 c(27.37 \mathrm{kal} / \mathrm{mol})$

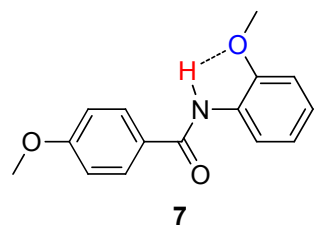

图 2 (a) 分子内三中心氢键酰胺 $\mathbf{5}$ 及其异构体 $\mathbf{5 a} \sim 5 \mathrm{c}$ 的结构, 以及(b)分子内两中心氢键酰胺 6 和 7 的结构

Figure 2 (a) Structures of amide 5 bearing intramolecular threecenter hydrogen bond and it's isomers $\mathbf{5 a} \sim \mathbf{5} \mathbf{c}$, and (b) structures of intramolecular two-center hydrogen bonded amides $\mathbf{6}$ and 7

响. 二维核磁共振(NOESY)实验数据显示, 与三中心氢 键邻近烷氧基上氢的 NOE 信号在氯仿中有明显增强, 这种现象在二甲亚砜中也能观测到，表明分子内三中心 氢键即使在极性溶剂中也能稳定存在。这种分子内三中 心氢键的存在，进一步通过 X 单晶衍射实验证实. 这是 第一次在所建立的芳香低聚酰胺模型体系中，证实了分 子内三中心氢键能稳定存在，并发现因 2 个不同部分的 协同作用而使分子构象固定. 此后，龚兵等 ${ }^{[21-22]}$ 对此类 三中心氢键体系做了更为深入的研究. 这些研究清楚表 明，分子内三中心氢键是一种高效且可靠的控制分子构 象的策略. 芳环的刚性以及分子内三中心氢键对分子构 象的限制作用，使得这一类芳香低聚酰胺具有较强的刚 性，容易形成弯月形的稳定构象。如果减少一个氢键, 分子骨架的刚性将减弱，通过缩合反应更易于形成聚合 物 ${ }^{[23]}$.

基于类似原理，研究者设计了各种各样的分子内三 中心氢键, 主要包括 $\mathrm{O} \cdots \mathrm{H} \cdots \mathrm{O}$ 型 $(\mathbf{8} \sim \mathbf{1 0})^{[13]} 、 \mathrm{~N} \cdots \mathrm{H} \cdots \mathrm{O}$ 型(11 和 12) $)^{[24-25]} 、 \mathrm{~N} \cdots \mathrm{H} \cdots \mathrm{N}$ 型 $(13 \text { 和 14 })^{[26-29]} 、 \mathrm{~S} \cdots \mathrm{H} \cdots$ $\mathrm{N}$ 型 $(\mathbf{1 5})^{[30-31]} 、 \mathrm{~S} \cdots \mathrm{H} \cdots \mathrm{O}$ 型 $(\mathbf{1 6})^{[32]} 、 \mathrm{~F} \cdots \mathrm{H} \cdots \mathrm{X}$ 型 $(X=F, N$, 17 19) ) $^{[33-35]}$ 等(图 3). 其中, $\mathrm{O} \cdots \mathrm{H} \cdots \mathrm{O}$ 型是最常见的一 大类分子内三中心氢键, 主要涉及的是各类被醚链或其

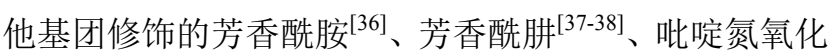
物 $^{[39]}$ 、酚氧负离子 ${ }^{[40]}$ 、芳香磺酰胺 ${ }^{[41-42]}$ 、吡啶酩 ${ }^{[43]}$ 等化 合物。 
<smiles>[R]Oc1c(C(=O)N(CCC)c2cccc(C(=O)NCC)c2O[R])cccc1N(C)C</smiles><smiles></smiles><smiles>[R]Oc1cc(OC)c(C(=O)N2c3cccc([Y])c3[Si]([R])[C-]2[R])cc1C(C)=O</smiles>

16

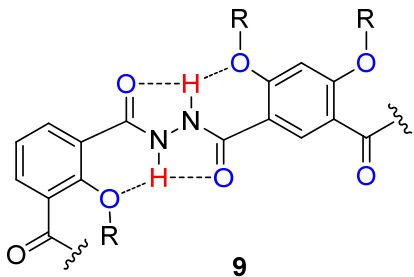<smiles></smiles>

13<smiles>CCN(C)C(=O)c1cccc(N(CC)C(=O)c2cccc(N(C)C)c2F)c1F</smiles>

17<smiles>[R]n1cc(C)c(=O)c(C(=O)Nc2cn([R])cc(C(=O)O)c2=O)c1</smiles><smiles></smiles>

11

图 3 不同类型的分子内三中心氢键

Figure 3 Different types of intramolecular three-center hydrogen bonds

\section{2 基于分子内三中心氢键的超分子构筑单元}

\section{1 折叠体}

多肽和蛋白质是生命的物质基础, 是构成细胞的基 本有机物, 是生命活动的主要承担者. 通常把少于 50 个 氨基酸的链称为肽, 而蛋白质一般有更长的链. 大自然 利用约二十种脂肪族 $\alpha$-氨基酸来构建肽和蛋白质的一 级结构, 然后通过非共价键作用力折叠、卷曲、螺旋、 缠绕等方式形成二级和高级结构. 为了模拟生物大分子 的二级结构, 研究人员设计了许多 $\beta-, \gamma-, \delta$-氨基酸和类 似的片段来构建人工二级结构. 其中, 具有分子内三中 心氢键的芳香低聚酰胺被公认为是一类极为有效和十 分可靠的可控折叠体系. 此外, 这些芳香低聚酰胺折叠 体, 可以进一步通过分子间的非共价键作用力自聚集或 与其他分子、离子络合形成不同的超分子组装体 ${ }^{[4-47]}$.

\section{$2.1 .1 \mathrm{O} \cdots \mathrm{H} \cdots \mathrm{O}$ 型}

2000 年, 龚兵等 ${ }^{[20]}$ 报道了首例基于 $\mathrm{O} \cdots \mathrm{H} \cdot \cdots \mathrm{O}$ 型分 子内三中心氢键诱导的六聚芳酰胺折叠体 (20, 图 4). 结 构中的分子内三中心氢键在诱导芳香低聚酰胺形成稳 定折叠构象方面起着极为重要的作用, 同时也起到了阻 止不利的分子间氢键形成的作用. 研究表明, 六聚物 20 折叠形成一个孔径约为 $1.0 \mathrm{~nm}$ 的环形空腔. 在这一研究 成果的基础上, 龚兵 ${ }^{[48]}$ 对三中心氢键诱导芳香低聚酰 胺形成具有中心孔穴结构的非天然折叠或螺旋分子做
了更为详尽的研究. 研究发现, 通过改变芳环上酰胺键 的位置, 此类芳香低聚酰胺可以形成内部孔径可调的折 叠或螺旋构象, 例如间间位(21, 六聚形成一个螺旋, 孔 径约 $1.0 \mathrm{~nm}$ )、间对位 $(\mathbf{2 2}$, 十二聚形成一个螺旋, 孔径约 $2.5 \mathrm{~nm})$ 、间对对位 $(\mathbf{2 3}$, 十八聚形成一个螺旋, 孔径约 $5.0 \mathrm{~nm}$ )等. 还可以通过改变骨架外围取代基的结构, 帮 助改善芳香低聚酰胺的溶解性.

在此基础上, 龚兵等 ${ }^{[49]}$ 研究发现此类具有折叠结 构的芳香低聚酰胺可以在非极性溶剂中聚集形成更大 的聚集体. 如单晶和粉末样品的 $\mathrm{X}$ 射线衍射数据所示, 五聚物 $\mathbf{2 4}$ 和六聚物 $\mathbf{2 5}$ 可以通过堆积作用组装形成柱状 聚集体. 为了系统地探讨低聚物长度、溶剂和温度对稳 定折叠短芳香低聚酰胺自缔合的影响, 龚兵等 ${ }^{[50]}$ 设计 合成了芳香低聚酰胺 26a 26f(图 5). 研究发现, 这些芳 香低聚酰胺自聚集强度不随低聚物长度线性增加. 与典 型的芳环堆积相反, 这些分子在低极性溶剂中的堆积增 强, 但在极性溶剂中, 尤其是氢键供体溶剂中的堆积大 大减弱. 此外, 聚集强度对温度变化非常敏感.

黎占亭等 ${ }^{[51]}$ 首次将酰肼官能团引入到构筑单元中, 通过简单衍生合成得到一系列芳香低聚酰肼类折叠体. 例如折叠体 27, 酰肼基团上的两个 $\mathrm{N}-\mathrm{H}$ 均能与苯环上 的烷氧基中的氧原子形成 $\mathrm{O} \cdots \mathrm{H} \cdots \mathrm{O}$ 型分子内三中心氢 键. 这两组三中心氢键分别处于骨架内外两侧, 导致分 子骨架刚性进一步增强. 在此基础上, 黎占亭等 ${ }^{[52]}$ 设计 


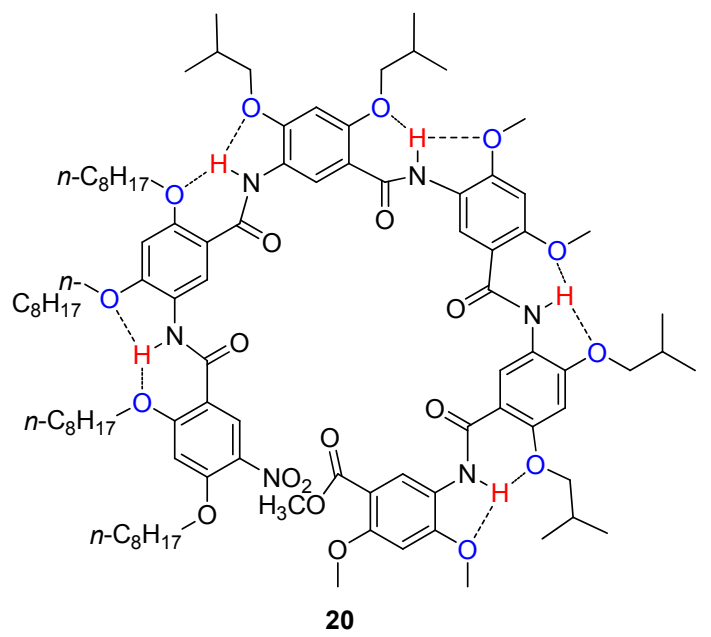

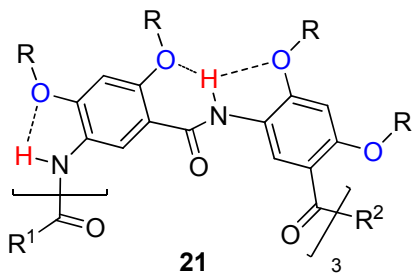<smiles>[R]Oc1cc(N(C)C([R])C)c(O[R])cc1C(=O)Nc1ccc(C([R])(C)C)c2c1OP([R])O2</smiles>

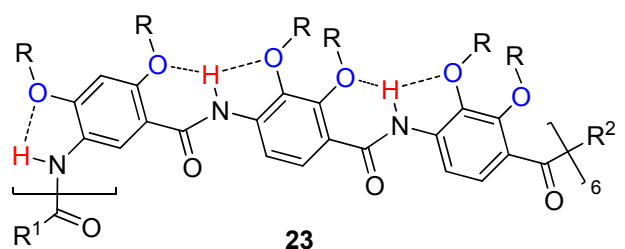

图 4 具有不同孔径的芳香低聚酰胺折叠体

Figure 4 Aromatic oligoamide foldamers with different internal diameters

合成了三种手性芳香族酰肼衍生物 $28 \mathbf{a} \sim 28 \mathbf{c}$ (图 6), 其 中两个 $R$-脯氨酸或 $S$-脯氨酸单元分别位于其骨架末端. ${ }^{1} \mathrm{H} N M R$ 、圆二色谱 $(C D)$ 、苂光实验和分子动力学模拟 表明, 这类折叠体具有手性螺旋构象, 在氯仿中与烷基 化葡萄糖配位具有良好的非对映选择性.

除酰胺、酰肼外, 研究者还构筑了很多其他类型 $\mathrm{O} \cdots \mathrm{H} \cdots \mathrm{O}$ 型分子内三中心氢键的折叠体, 例如吡啶氮 氧化物 ${ }^{[39]}$ 、酚氧负离子 ${ }^{[40]}$ 等. 陈传峰等 ${ }^{[39]}$ 利用吡啶氮氧 化物-2,6-二甲酰氯为原料, 合成了磺酰胺-酰胺杂化低 聚物 29(图 7). 在固态下, 29 的酰胺氢原子能与吡啶氮氧 化物中的氧负离子和磺胺中的一个氧原子形成 $\mathrm{O} \cdots \mathrm{H} \cdots$ $\mathrm{O}$ 型分子内三中心氢键, 并驱使分子骨架扭曲为锯齿形 的构象. 黎占亭等 ${ }^{[40}$ 设计在 -5 - 甲基- 2 - 甲氧基-

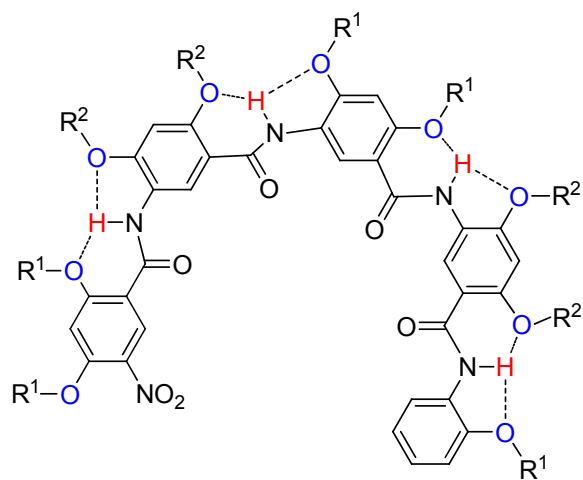

24a: $\mathrm{R}^{1}=\mathrm{CH}_{2} \mathrm{CH}_{2} \mathrm{OC}\left(\mathrm{CH}_{3}\right)_{3} ; \mathrm{R}^{2}=\mathrm{CH}_{3}$ 24b: $\mathrm{R}^{1}=\mathrm{CH}_{3} ; \mathrm{R}^{2}=\left(\mathrm{CH}_{2} \mathrm{CH}_{2} \mathrm{O}\right)_{3} \mathrm{CH}_{3}$

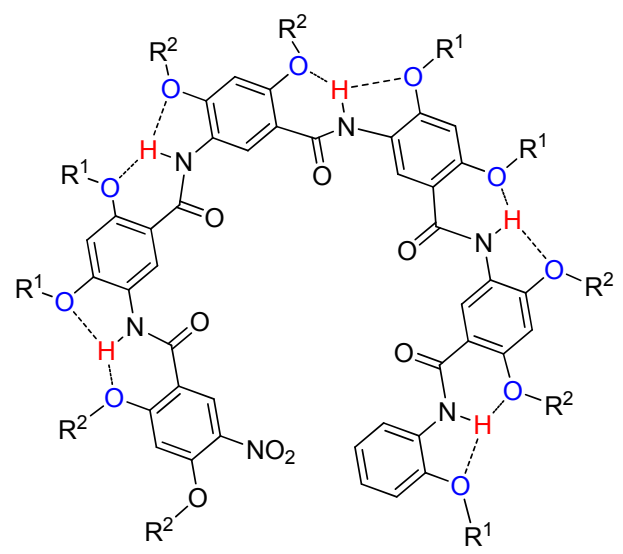

25a: $\mathrm{R}^{1}=\mathrm{CH}_{2} \mathrm{CH}_{2} \mathrm{OC}\left(\mathrm{CH}_{3}\right)_{3} ; \mathrm{R}^{2}=\mathrm{CH}_{3}$

25b: $\mathrm{R}^{1}=\mathrm{CH}_{3} ; \mathrm{R}^{2}=\left(\mathrm{CH}_{2} \mathrm{CH}_{2} \mathrm{O}\right)_{3} \mathrm{CH}_{3}$

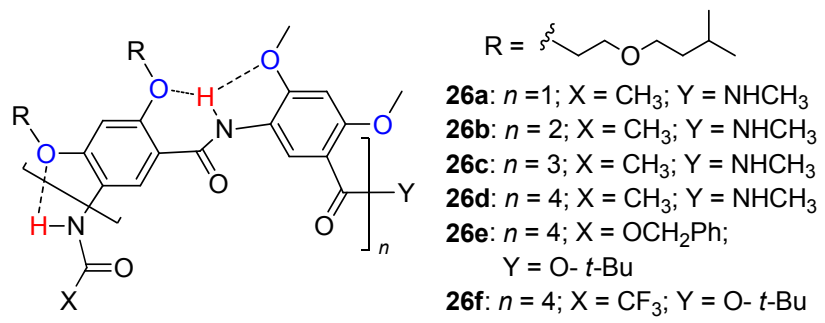

图 5 芳香低聚酰胺折叠体 24 26 的结构

Figure 5 Structures of aromatic oligoamide foldamers $\mathbf{2 4} \sim \mathbf{2 6}$

3-氨基苯甲酸聚合过程中加入 $\mathrm{LiCl}$, 得到约 71\%的去甲 基化聚合物 30(图 7). 由于缺乏分子内三中心氢键作用, 这种含酚芳香低聚酰胺本质上应为线性结构. 有趣的 是，当寡聚物 30 在碱性条件下去质子形成酚氧负离子 寡聚芳酰胺 31 时，则会形成 $\mathrm{O} \cdots \mathrm{H} \cdots \mathrm{O}$ 型分子内三中心 氢键, 从而产生螺旋构象.

2.1.2 $\mathrm{N} \cdots \mathrm{H} \cdots \mathrm{X}(\mathrm{X}=\mathrm{N} 、 \mathrm{O})$ 型

如果用含氮杂芳环替代苯环，则能合成具有 $N \cdots$ $\mathrm{H} \cdots \mathrm{N}$ 型分子内三中心氢键的折叠体. 例如 Berl 等 ${ }^{[53]}$ 设 计合成了由吡啶酰胺单元构成的低聚物 32(图 8), 在分 子内三中心氢键的诱导下实现骨架刚性化，并形成稳定 的单螺旋结构. 在非极性溶剂中, 这些低聚吡啶酰胺螺 旋体能通过分子间非共价键作用自组装形成双螺旋结. 


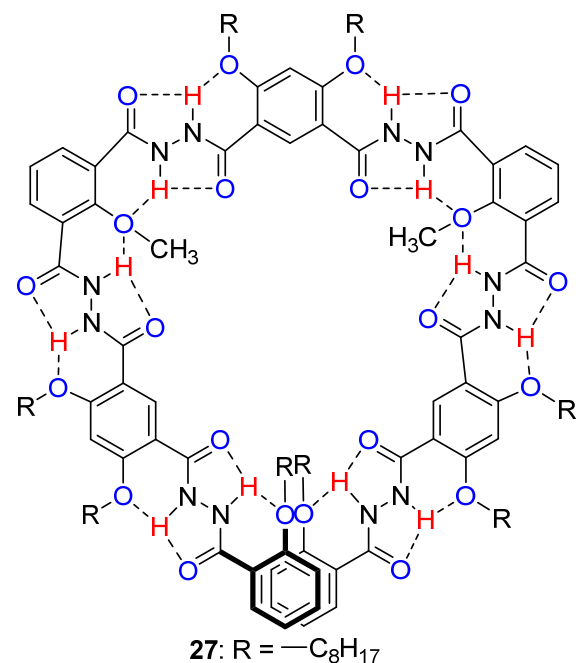

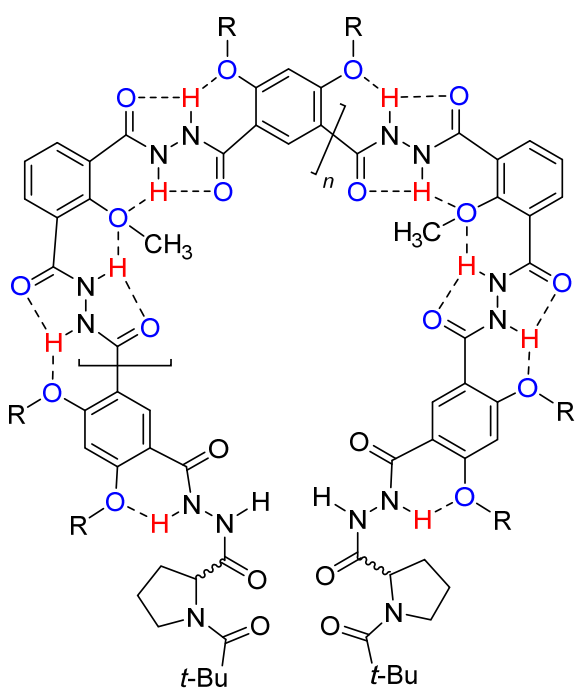

28a: $n=1(R, R)$

28b: $n=2(R, R) \quad \mathrm{R}=-\left(\mathrm{CH}_{2} \mathrm{CH}_{2} \mathrm{O}\right)_{2} \mathrm{Et}$

28c: $n=2(S, S)$

图 6 低聚芳香酰肼折叠体 27 和 28 的结构

Figure 6 Structures of aromatic oligohydrazide foldamers 27 and 28

构. Shirude 等 ${ }^{[54]}$ 研究发现, 如果采用 8-氨基-2-喹啉羧酸 为原料, 则可以合成得到低聚喹啉酰胺折叠体 33(图 8).

在此基础上，江华等 ${ }^{[55-57]}$ 将手性基团引入低聚喹啉 酰胺折叠体的 $\mathrm{N}$-端或 $\mathrm{C}$-端, 可以诱导其形成手性螺旋 体. 例如, 江华等 ${ }^{[55}$ 将手性 $\beta$-蒎烯衍生吡啶酸引入寡聚 喹啉酰胺折叠体的 $\mathrm{N}$-端, 合成得到手性螺旋低聚物 34 . 其中, $\beta$-蒎烯衍生吡啶基不仅具有较大的空间位阻, 而 且能与邻近的喹啉酰胺形成 $\mathrm{N} \cdots \mathrm{H} \cdots \mathrm{N}$ 型分子内三中心 氢键, 因此具有很强的手性诱导作用. 江华等 ${ }^{[56]}$ 还报道 了通过在非手性寡聚喹啉酰胺折叠体的 $\mathrm{C}$ 端引入手性 啞唑苯胺基团来定量诱导其形成单手性螺旋体 ( $\mathrm{P}$ 或者 $\mathrm{M})$, 发光不对称因子 $\left(g_{\text {lum }}\right)$ 高达 0.038 . 更重要的是, 随 着寡聚喹啉酰胺折叠体长度的增加, 圆偏振发光

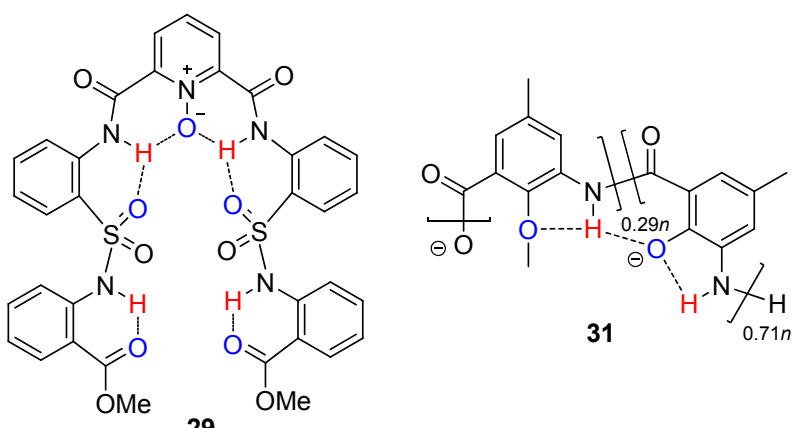

29<smiles>COc1c(NC(C)C)cc(C)cc1C(=O)CN(C)c1cc(C)cc(C(=O)O)c1OC</smiles>

图 7 化合物 29 31 的结构

Figure 7 Structures of compounds $29 \sim 31$

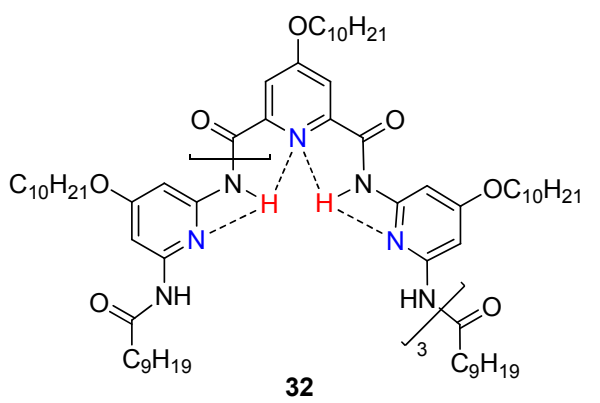

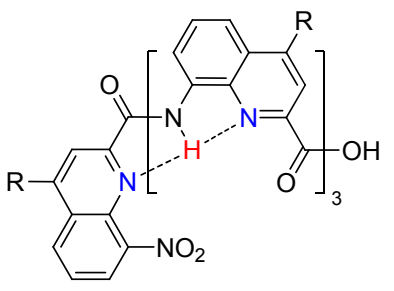

33: $\mathrm{R}=-\mathrm{O}\left(\mathrm{CH}_{2}\right)_{3} \mathrm{NH}_{3}{ }^{+} \mathrm{CF}_{3} \mathrm{CO}_{2}{ }^{-}$
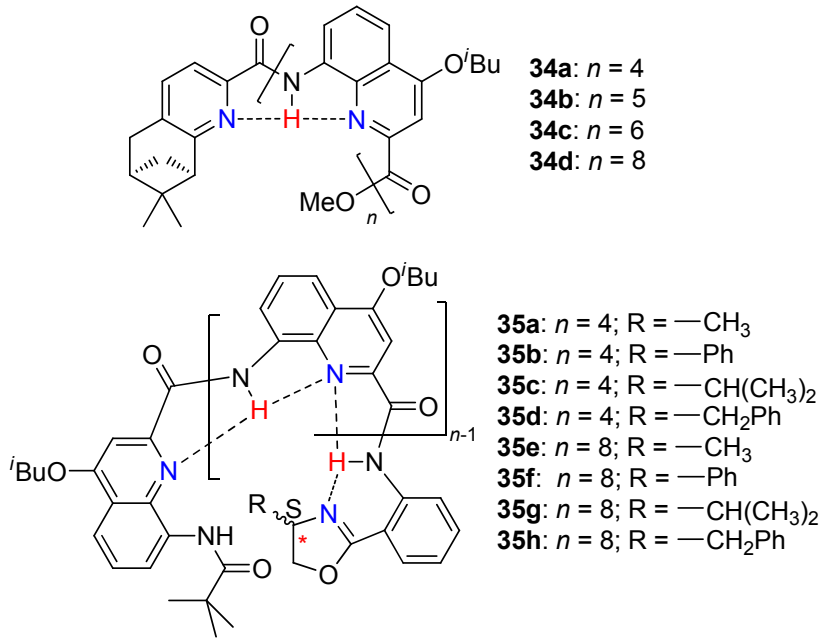

图 8 化合物 $32 \sim 35$ 的结构

Figure 8 Structures of compounds 32 $\mathbf{3 5}$ 
(CPL) 不对称因子和吸收不对称因子一起增强. 为了进 一步了解手性留唑苯胺基团对单手性螺旋度的定量诱 导, 江华等 ${ }^{[57]}$ 设计并合成了手性噁唑苯胺中含有不同 取代基的四聚和八聚的寡聚喹啉酰胺折叠体 35(图 8), 并探讨了取代基大小对其手性诱导的影响. 研究发现, 吸收和发射不对称因子均取决于寡聚喹啉酰胺折叠体 的长度, 而与手性噁唑苯胺中残基的大小无关.

陈传峰等 ${ }^{[24]}$ 利用吡啶-2,6-二甲酰氯为原料, 合成了 磺酰胺-酰胺杂化低聚物 36(图 9). 在固态下, 36 的酰胺 氢原子能与吡啶中的氮原子和磺胺中的一个氧原子形 成 $\mathrm{N} \cdots \mathrm{H} \cdots \mathrm{O}$ 型分子内三中心氢键. $\mathrm{X}$ 射线晶体学分析结 果显示, 在分子内三中心氢键的控制下, 化合物 36 扭曲 为二维片状构象, 并进一步自组装形成管状结构. 姚建 年等 ${ }^{[26-27]}$ 设计合成了一系列吡啶一酰亚胺低聚物 37a 37f(图 9). 研究发现, 酰亚胺基团中的 $\mathrm{N}-\mathrm{H}$ 能与两个 相邻吡啶基团中的 $\mathrm{N}$ 原子形成 $\mathrm{N} \cdots \mathrm{H} \cdots \mathrm{N}$ 型分子内三中 心氢键, 促使吡啶一酰亚胺低聚物形成高度紧密和稳定 的螺旋构象. 37b 和 $37 \mathrm{c}$ 的晶体结构表明, 每五个单位构 成一个螺旋, 即每个螺旋主干上包含大约 15 个原子.

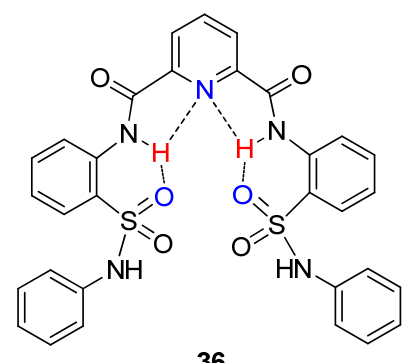

36

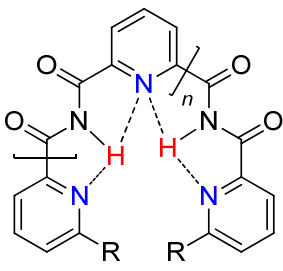

37a: $n=0, \mathrm{R}=\mathrm{CO}_{2} \mathrm{Et}$

37b: $n=1, \mathrm{R}=\mathrm{CO}_{2} \mathrm{Et}$

37c: $n=2, \mathrm{R}=\mathrm{CO}_{2} \mathrm{Et}$

37d: $n=1, \mathrm{R}=\mathrm{CO}_{2}\left(\mathrm{CH}_{2}\right)_{3} \mathrm{Cl}$ 37e $n=2, \mathrm{R}=\mathrm{CO}_{2}\left(\mathrm{CH}_{2}\right)_{3} \mathrm{Cl}$ 37f: $n=3, \mathrm{R}=\mathrm{CO}_{2}\left(\mathrm{CH}_{2}\right)_{3} \mathrm{Cl}$

图 9 化合物 36 和 37 的结构

Figure 9 Structures of compounds $\mathbf{3 6}$ and $\mathbf{3 7}$

\subsection{3 $\mathrm{F} \cdots \mathrm{H} \cdots \mathrm{X}(\mathrm{X}=\mathrm{F}, \mathrm{O}, \mathrm{N})$ 型}

尽管卤素原子的电负性比较大, 但是共价键合的卤 素原子一直以来被认为是很弱的氢键受体. 江华 ${ }^{[34-35]}$ 和 黎占亭等 ${ }^{\left[{ }^{58-59]}\right.}$ 研究发现, 卤素原子可以作为芳酰胺氢的 良好氢键受体, 形成五元环或六元环的分子内氢键. 尤 其是氟原子, 无论在晶体还是在溶液中, 它都能与芳酰 胺氢结合形成较强的分子内氢键, 甚至可以同时与两个 邻近的酰胺氢键结合.

江华等 ${ }^{[34-35]}$ 利用 7-氨基-8-氟(氯)-2-喹啉羧酸衍生 物为原料, 合成得到喹啉酰胺低聚物 $38 \mathrm{a} \sim 38 \mathrm{e}$ (图 10). 在分子内三中心氢键驱使下, 它们能形成具有纳米螺旋 空腔的单螺旋结构. 通过分子间作用力, 这些单螺旋结 构可以自组装形成双螺旋和四螺旋超分子聚集体. 进一

步研究发现, 如果在喹啉酰胺低聚物的 C-端引入手性 基团(38c), 则诱导形成具有手性的双螺旋聚集体. 此 外, 卤素原子为氯原子时, 喹啉酰胺低聚物具有相似的 组装性质. 例如, 38e 不仅能自聚集形成具有双螺旋结 构的同二聚体 $(\mathbf{3 8 e})_{2}$, 还能与 $\mathbf{3 8 b}$ 通过交叉杂化形成异 二聚体 38b・38e.<smiles>[R]c1c(NC(C)(C)C(C)(C)C)ccc2c(OC)cc(C(=O)C([R])C)nc12</smiles>

图 10 喹啉酰胺低聚物 38a $38 \mathrm{e}$ 的结构

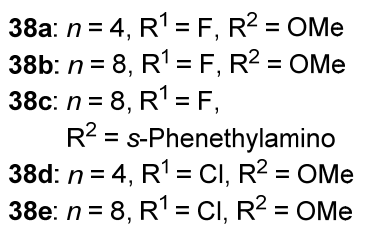

Figure 10 Structures of quinoline amide oligomers $38 \mathbf{a} \sim 38 \mathrm{e}$

黎占亭等 ${ }^{[60]}$ 设计合成了芳环被氟原子修饰的芳香 低聚酰胺 39 和 40(图 11). 其中, 酰胺氢能与两个邻近的 氟原子形成 $\mathrm{F} \cdots \mathrm{H} \cdots \mathrm{F}$ 型分子内三中心氢键. 在分子内 三中心氢键的诱导和限制下，这些芳香低聚酰胺能够形 成稳定的折叠构象. 进一步研究发现, 它们可以通过分 子间的静电作用和 $\mathrm{N}-\mathrm{H} \cdots \mathrm{F}$ 氢键作用与脂肪胺形成稳 定的络合物. 此外, 基于 $\mathrm{F} \cdots \mathrm{H} \cdots \mathrm{F}$ 型分子内三中心氢键 形成的折叠体还可以自组装形成超分子纳米网络结 构 ${ }^{[6]}$ 或者囊泡 ${ }^{[62]}$.

除了酰胺 $\mathrm{N}-\mathrm{H}$ 外, 某些类型的 $\mathrm{C}-\mathrm{H}$ 也能形成分 子内三中心氢键. 例如, 1,2,3-三氮唑的 $\mathrm{C}(5)-\mathrm{H}$ 原子是 一个较弱的氢键供体，但能用于诱导苯-三氮唑交替低 聚物折叠成螺旋构象 ${ }^{[63]}$. 黎占亭等 ${ }^{[64]}$ 报道了首例由三 氮唑 $\mathrm{C}-\mathrm{H}$ 形成的 $\mathrm{F} \cdots \mathrm{H} \cdots \mathrm{F}$ 型三中心氢键稳定的人工二 级结构. 他们设计以 2,4-二氟-5-硝基苯胺和 1,5-二乙炔 基-2,4-二氟苯为原料，依次通过叠氮化、1,3-偶基环加 成、硝基还原等反应合成了分别含有 $2 、 4 、 6$ 和 8 个 $1,2,3-$ 三氮唑单元的低聚物 41a 41d(图 12). 其中, 三氮唑单 元中的 $\mathrm{C}-\mathrm{H}$ 能与两个邻近的 $\mathrm{F}$ 原子形成指向骨架外侧 的 $\mathrm{F} \cdots \mathrm{H} \cdots \mathrm{F}$ 型分子内三中心氢键，并驱动骨架形成稳 定的折叠构象. 基于类似原理, 江华等 ${ }^{\left[{ }^{[5]}\right.}$ 以 4-氟苯甲酸 异丁酯为原料, 设计合成了具有指向骨架内侧 $\mathrm{F} \cdots \mathrm{H} \cdots \mathrm{F}$ 型分子内三中心氢键的低聚芳基三氮唑折叠体 42 (图 12).

\section{2 大环化合物}

大环化合物是一类十分重要的有机分子, 它的合成 方法研究一直是有机合成化学的一个重要研究领域. 在 合成过程中, 由于存在大量具有活性端基的低聚前体, 大环化合物的形成始终面临着低聚体或聚合物等线性 副产物的竞争. 为提高成环效率, 人们提出了模板法、 高度稀释、动态共价键法以及结构预组织等策略. 其中, 

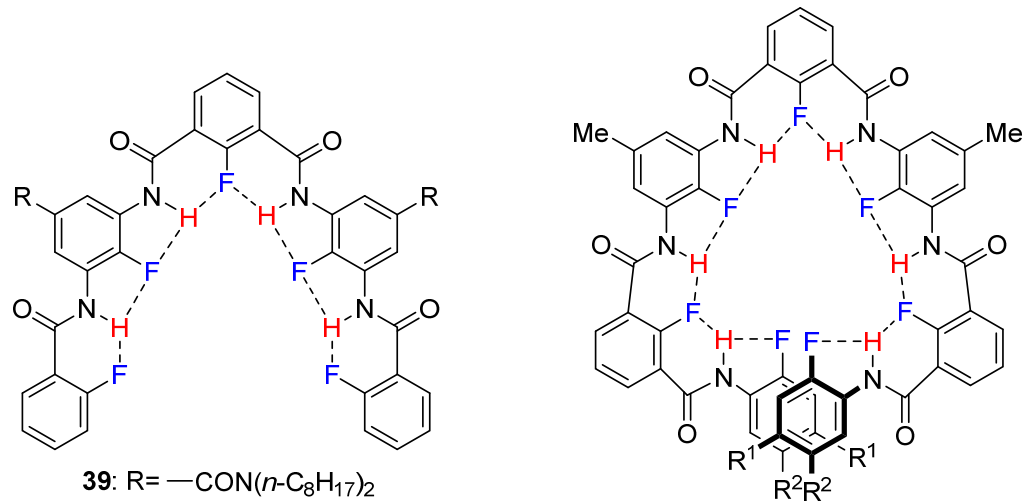

40a: $\mathrm{R}^{1}=\mathrm{H}, \mathrm{R}^{2}=-\mathrm{CON}\left(n-\mathrm{C}_{8} \mathrm{H}_{17}\right)_{2}$

40b: $\mathrm{R}^{1}=\mathrm{Me}, \mathrm{R}^{2}=-\operatorname{CON}\left(n-\mathrm{C}_{8} \mathrm{H}_{17}\right)_{2}$

图 11 基于 $\mathrm{F} \cdots \mathrm{H} \cdots \mathrm{F}$ 型分子内三中心氢键的低聚芳香酰胺折叠体

Figure 11 Aromatic oligoamide foldamers induced by the $\mathrm{F} \cdots \mathrm{H} \cdots \mathrm{F}$ type intramolecular three-center hydrogen bond

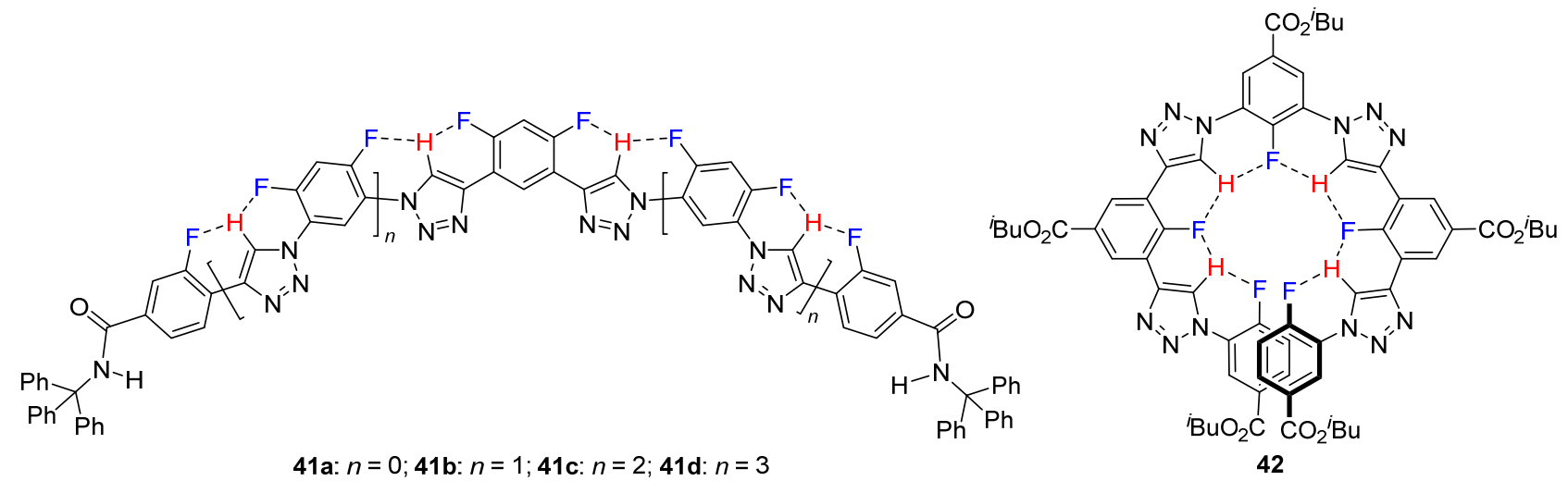

图 12 基于 $\mathrm{C}-\mathrm{H}$ 形成的 $\mathrm{F} \cdots \mathrm{H} \cdots \mathrm{F}$ 型分子内三中心氢键的折叠体

Figure 12 Foldamers based on the $\mathrm{F} \cdots \mathrm{H} \cdots \mathrm{F}$ type intramolecular three-center hydrogen bond formed by $\mathrm{C}-\mathrm{H}$

结构预组织策略是通过控制单体或线性前体的几何形 状或构象, 使最后一步成环前体自发形成折叠构象, 诱 导促进两个端基反应位点在空间上相互接近, 从而促进 大环结构的产生.

龚兵等 ${ }^{[6]}$ 在明确分子内三中心氢键能诱导线性分 子形成特定的折叠或螺旋构象的基础上, 首先发现并提 出利用分子内三中心氢键促进大环化合物的高效合成 策略. 此后, 该策略越来越受到研究者关注. 在分子内 三中心氢键的诱导和驱使下, 人们合成了各种各样的大 环，例如芳酰胺类、芳酰肼类、芳香磺酰胺类、喹啉类、 吡啶类等大环分子. 由于三中心氢键对大环骨架的限 制，这些大环分子倾向于形成刚性的类平面构象，可以 通过 $\pi-\pi$ 堆积、氢键、溶剂效应及范德华力等非共价键 作用力, 进一步组装形成微球、纳米管、纳米线和囊泡 等不同类型的超分子组装体 ${ }^{[67-70]}$.

\subsection{1 $\mathrm{O} \cdots \mathrm{H} \cdots \mathrm{O}$ 型}

2004 年, 龚兵等 ${ }^{[66]}$ 在利用邻位二烷氧基取代的间 苯二酰氯和 4,6-二甲氧基-1,3-苯二胺合成折叠体的过程 中发现当降低反应体系的温度时, 环状化合物 43 的产
率显著增加 $\left(-20{ }^{\circ} \mathrm{C}\right.$, 产率高达 $\left.80 \%\right)$. 龚兵等认为, 分 子内三中心氢键的固定作用, 限制了相关共价键的自由 转动, 使得低聚前体的骨架采取弯曲构象, 进而促进高 效成环(图 13). 龚兵等 ${ }^{[71]}$ 对高效成环的机理进行了深入 研究, 发现除分子内三中心氢键对低聚前体骨架构象限 制作用外，成环的高效性还与远程位阻效应有关. 这种 成环方法不仅原料简单、合成方便, 还能避免引入新的 模板分子. 此外, 龚兵等 ${ }^{[72]}$ 研究还发现通过改变此类大 环外围取代基的结构可以改变其聚集行为.

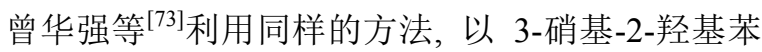
甲酸甲酯为起始原料, 经醚化、还原、水解、缩合等反 应, 高效地合成得到五聚芳酰胺大环 44a(图 13), 产率 为 $62 \%$. 在处于环内的 $\mathrm{O} \cdots \mathrm{H} \cdots \mathrm{O}$ 型三中心氢键的限制 下, 此五聚环能够保持一个较好的平面结构. 随后, 曾 华强等 ${ }^{[74]}$ 采用不同聚集度的线性寡聚氨基酸和单体氨 基酸为原料，在分子内三中心氢键促进和引导下，一锅 法高效地合成了杂化五聚大环 $\mathbf{4 4 b \sim 4 4 h}$ (图 13).

在明确了寊聚芳香酰胺中的 $\mathrm{O} \cdots \mathrm{H} \cdots \mathrm{O}$ 型分子内三 中心氢键对分子构象的控制作用后, 研究者将此策略扩 


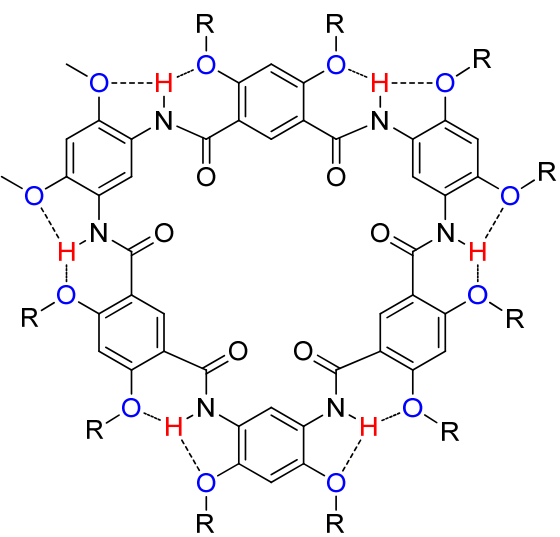

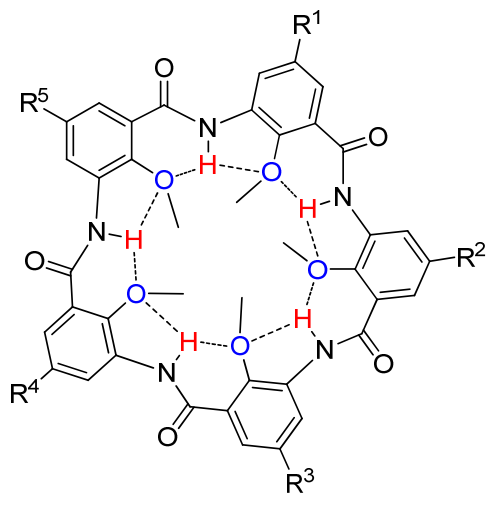

44a: $R^{1}=R^{2}=R^{3}=R^{4}=R^{5}=H$

44b: $R^{1}=R^{2}=R^{3}=R^{4}=R^{5}=O_{8} H_{17}$

44c: $R^{1}=R^{2}=R^{3}=R^{4}=\mathrm{OC}_{8} \mathrm{H}_{17} ; R^{5}=H$

44d: $\mathrm{R}^{1}=\mathrm{R}^{2}=\mathrm{R}^{4}=\mathrm{OC}_{8} \mathrm{H}_{17} ; \mathrm{R}^{3}=\mathrm{R}^{5}=\mathrm{H}$

44e: $R^{1}=R^{2}=R^{3}=O_{8} H_{17} ; R^{4}=R^{5}=H$

44f: $R^{1}=R^{2}=R^{4}=H ; R^{3}=R^{5}=O_{8} H_{17}$

44g: $R^{1}=R^{2}=R^{3}=H ; R^{4}=R^{5}=O_{8} H_{17}$

44h: $R^{1}=R^{2}=R^{3}=R^{4}=H ; R^{5}=O_{8} H_{17}$

43a: $\mathrm{R}=-n-\mathrm{C}_{8} \mathrm{H}_{17} ;$ 43b: $\mathrm{R}=-\left(\mathrm{CH}_{2}\right)_{3} \mathrm{CO}_{2} \mathrm{CH}_{2} \mathrm{CH}_{3}$

43c: $\mathrm{R}=-\left(\mathrm{CH}_{2} \mathrm{CH}_{2} \mathrm{O}\right)_{3} \mathrm{CH}_{3}$

图 13 六聚芳酰胺大环 $\mathbf{4 3}$ 和五聚芳酰胺大环 $\mathbf{4 4}$ 的结构

Figure 13 Structures of hexameric arylamide macrocycles 43 and pentameric arylamide macrocycles 44

(a)

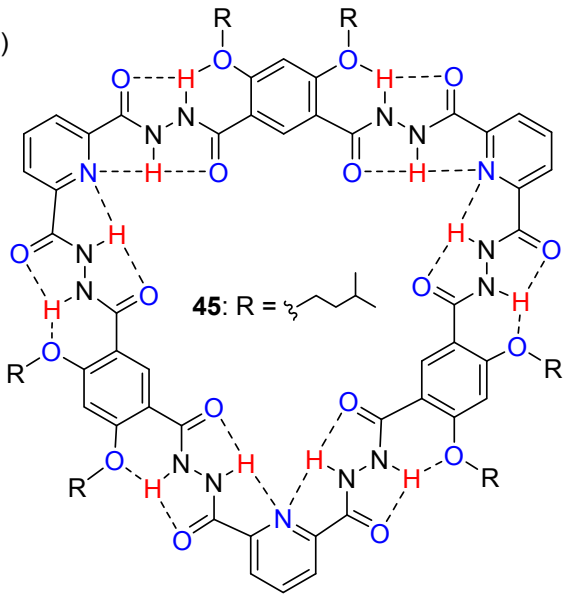

(b)

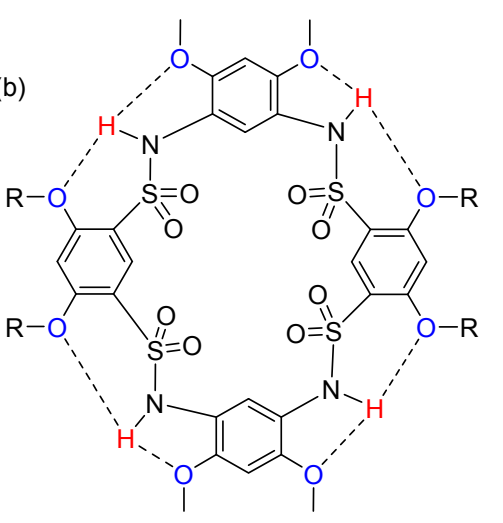

47a: $\mathrm{R}=n-\mathrm{C}_{3} \mathrm{H}_{7} ; \mathbf{4 7 b}: \mathrm{R}=n-\mathrm{C}_{5} \mathrm{H}_{11}$

47c: $\mathrm{R}=i-\mathrm{C}_{3} \mathrm{H}_{7} ;$ 47d: $\mathrm{R}=i-\mathrm{C}_{5} \mathrm{H}_{11}$

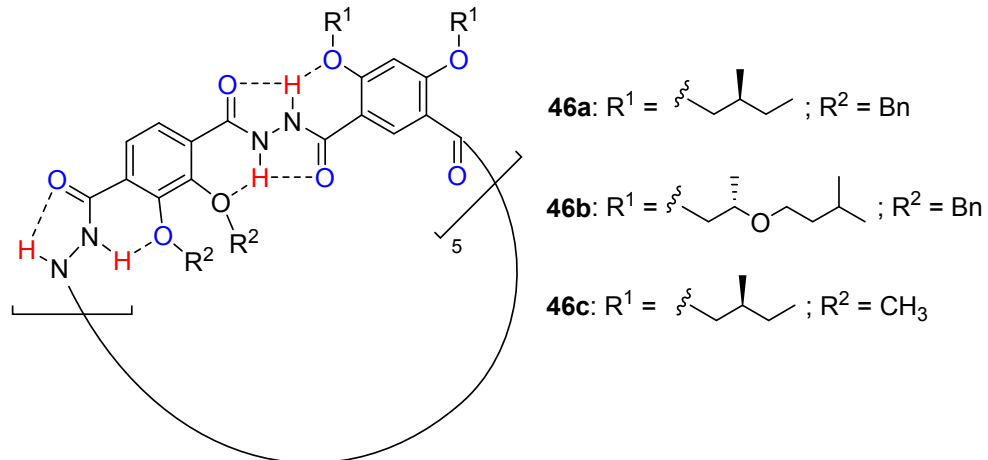

(c)

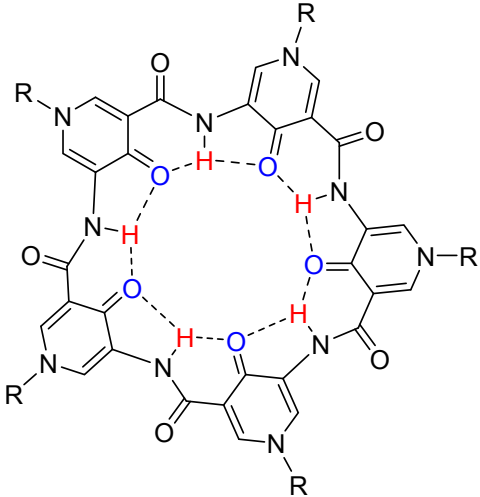

49a: $\mathrm{R}=$ iso-butyl; 49b: $\mathrm{R}=\mathrm{C}_{8} \mathrm{H}_{17}$

48a: $\mathrm{R}=n-\mathrm{C}_{7} \mathrm{H}_{15}$

49c: $\left.\mathrm{R}=\mathrm{CH}_{2} \mathrm{CH}_{2} \mathrm{OCH}_{2} \mathrm{CH}_{3} ; 49 \mathrm{~d}: \mathrm{R}=\mathrm{CH}_{2} \mathrm{CH}_{2} \mathrm{O}\right)_{2} \mathrm{CH}_{3}$

49e: $\mathrm{R}=\left(\mathrm{CH}_{2} \mathrm{CH}_{2} \mathrm{O}\right)_{2} \mathrm{CH}_{3} ; 49 \mathrm{f}: \mathrm{R}=\mathrm{Bn}$

图 14 (a)芳香低聚酰肼大环 $(45$ 和 46)、(b)四聚芳香磺酰胺大环 $(47$ 和 48)、(c)五聚吡啶酮酰胺大环 (49)

Figure 14 (a) Aromatic oligohydrazide macrocycles (45 and 46), (b) tetrameric aromatic sulfonamide macrocycles (47 and 48$)$, and (c) pentameric pyridone amide macrocycles (49)

展至很多其他体系. 例如, 龚兵等 ${ }^{[37]}$ 采用单体二酰氯和 单体二酰肼作原料, 在两组三中心氢键的诱导下, 高效 地合成外围和内腔均可调节的芳酰肼类大环 45 和 $\mathbf{4 6}$, 最高产率可达 97\%(图 14). 通过改变外围侧链, 可以调
节大环的溶解度．通过改变取代基位置(间位或对位), 可以调节大环内腔的尺寸. 何兰和龚兵等 ${ }^{[41-42]}$ 设计合成 了寡聚芳香磺酰胺，也能在骨架外侧形成由一个五元环 和一个六元环组成的 $\mathrm{O} \cdots \mathrm{H} \cdots \mathrm{O}$ 型分子内三中心氢键, 
并诱导其形成稳定的弯月形分子骨架. 在这种分子内三 中心氢键的驱使下, 利用苯二磺酰氯(或䒺二磺酰氯)和 间苯二胺为原料, 能高效地合成在溶液和固体状态下均 保持稳定雉形构象的含烷氧基侧链的芳香四聚磺酰胺 大环 47 和 48(图 14). 曾华强等 ${ }^{[43]}$ 首次以吡啶酮为单体, 通过分子内三中心氢键的促进和引导, 一锅法高效地合 成了吡啶酮类五聚大环 49(图 14).

\subsection{2 $\mathrm{N} \cdots \mathrm{H} \cdots \mathrm{X}(\mathrm{X}=\mathrm{N}, \mathrm{O})$ 型}

早在 2000 年, Berl 等 ${ }^{[53]}$ 研究发现 $\mathrm{N} \cdots \mathrm{H} \cdots \mathrm{N}$ 型分子 内三中心氢键能诱导芳香低聚酰胺形成折叠体. 在此基 础上, Huc 等 ${ }^{[28]}$ 采用 8-氨基-2-喹啉羧酸为原料, 合成得 到骨架内侧含有 $\mathrm{N} \cdot \cdots \mathrm{H} \cdot \cdots \mathrm{N}$ 型分子内三中心氢键的三聚 喹啉酰胺大环 50、四聚喹啉酰胺 51(图 15). 此后, Huc 等 ${ }^{[29]}$ 还报道了采用 1,8 -二氮杂-4,5-二烷氧基-2,7-葱二羧 酸衍生物和 2,6-吡啶二胺为原料, 通过缩合反应得到四 聚大环 52, 该体系也通过分子内 $\mathrm{N} \cdots \mathrm{H} \cdots \mathrm{N}$ 型三中心氢 键的形成来实现骨架刚性化(图 15).

江华等 ${ }^{[25]}$ 以 2-甲氧基-3-硝基苯胺为起始原料，通 过四步反应合成得到喹啉氨基酸衍生物. 在二氯三苯基 膦存在下, 相应喹啉氨基酸在干燥的四氢呋喃(THF)中 回流缩合, 可以形成内腔为 $\mathrm{N} \cdots \mathrm{H} \cdots \mathrm{O}$ 型分子内三中心 氢键的四聚喹啉大环 $53 \mathrm{a}$ 和 $53 \mathrm{~b}$, 产率分别为 $46 \%$ 和 53\%(图 15). 分子内三中心氢键对非环化中间体构象的 预组织, 促进了此类大环的高效合成.

除 $\mathrm{N}-\mathrm{H}$ 外, $\mathrm{C}-\mathrm{H}$ 也能形成 $\mathrm{N} \cdots \mathrm{H} \cdots \mathrm{N}$ 型分子内三 中心氢键并用于诱导大环合成. Cuccia 等 ${ }^{[75]}$ 报道了用 2,7-二氨基-1,8-菱啶和原甲酸三乙酯为原料，一锅法高 效地合成了甲脒键连接的大环 54 , 分离产率高达 $75 \%$ (图 16). 甲脒基团中的 $\mathrm{C}-\mathrm{H}$ 指向环的内部, 并于邻近 萗啶基团上的 $\mathrm{N}$ 原子形成 $\mathrm{N} \cdots \mathrm{H} \cdots \mathrm{N}$ 型分子内三中心氢 键. 分子内三中心氢键的形成, 不仅诱导了大环 $\mathbf{5 4}$ 的高 效合成，并促使其形成近平面结构.

\subsubsection{F $\cdots \mathrm{H} \cdots \mathrm{X}(\mathrm{X}=\mathrm{F}, \mathrm{O}, \mathrm{N})$ 型}

黎占亭等 ${ }^{[76]}$ 研究发现, 可以通过 $F \cdots H \cdots F$ 型或 $F \cdots$ $\mathrm{H} \cdots \mathrm{N}$ 型分子内三中心氢键诱导形成大环. 例如, 在氯 仿中有三乙胺存在下, 采用 2-氟-1,3-苯二胺衍生物和 2氟间苯二甲酰氯为原料, 可以合成得到含有 $\mathrm{F} \cdots \mathrm{H} \cdots \mathrm{F}$ 型三中心氢键的六聚体大环 55. 如果采用吡啶-2,6-二甲 酰氯和 2-氟-1,3-苯二胺衍生物为原料, 则同时得到二聚 体 56、四聚体 57 和六聚体 58 的混合物，总产量在 $80 \%$ 左右(图 17). 其中, 大环 $\mathbf{5 7}$ 和 $\mathbf{5 8}$ 刚性环的内侧存在 F $\cdots$ $\mathrm{H} \cdots \mathrm{N}$ 型三中心氢键.

\section{3 线性拓展化合物}

分子内三中心氢键诱导的芳酰胺除了能形成折叠

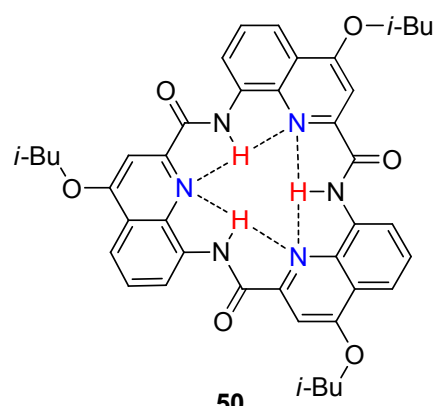

50

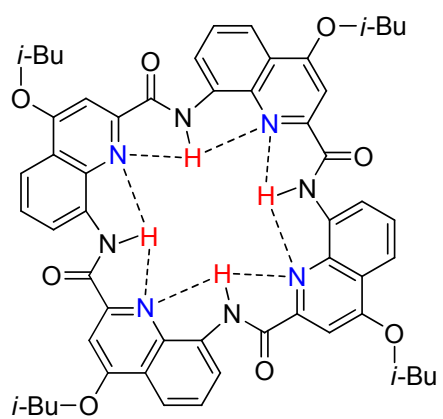

51

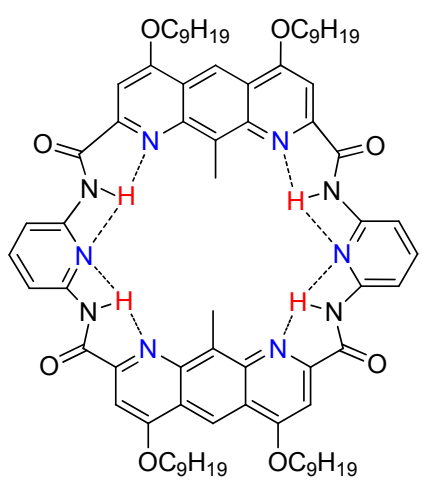

52

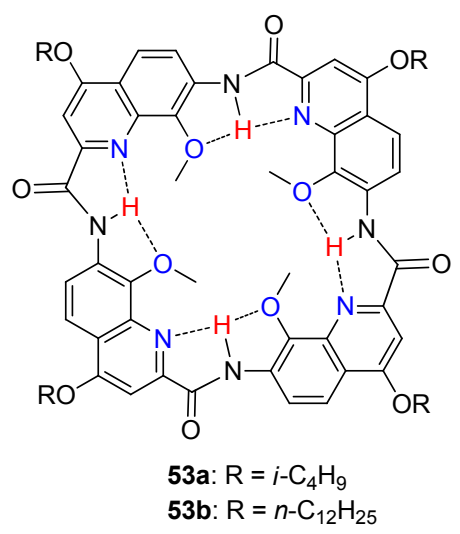

图 15 基于 $\mathrm{N} \cdots \mathrm{H} \cdots \mathrm{X}(\mathrm{X}=\mathrm{N}, \mathrm{O})$ 型分子内三中心氢键的大环 Figure 15 Macrocycles based on the $\mathrm{N} \cdots \mathrm{H} \cdots \mathrm{X}(\mathrm{X}=\mathrm{N}, \mathrm{O})$ typed intramolecular three-center hydrogen bond

或螺旋构象外，还可以通过改变芳环上酰胺基团和氢键 受体的位置, 使这类分子骨架形成直线型及其他扩展型 的构象. 


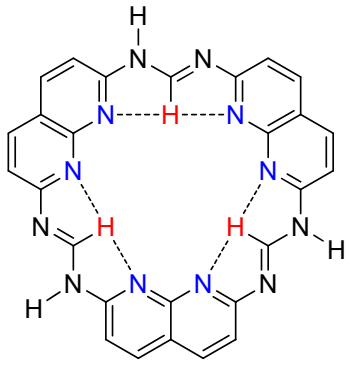

54

图 16 基于 $\mathrm{C}-\mathrm{H}$ 形成的 $\mathrm{N} \cdots \mathrm{H} \cdots \mathrm{N}$ 型分子内三中心氢键的大 环

Figure 16 Macrocycle based on the $\mathrm{N} \cdots \mathrm{H} \cdots \mathrm{N}$ typed intramolecular three-center hydrogen bond formed by $\mathrm{C}-\mathrm{H}$

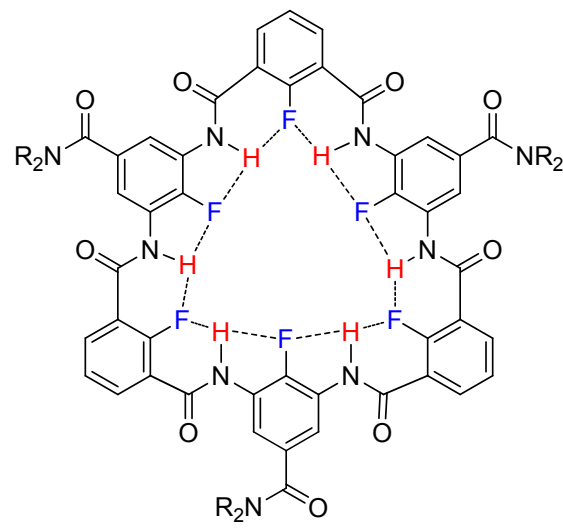

55<smiles>[R20]NC(=O)c1cc2[nH]c(=O)c3cccc(n3)c(=O)[nH]c(c1)c2F</smiles>

56

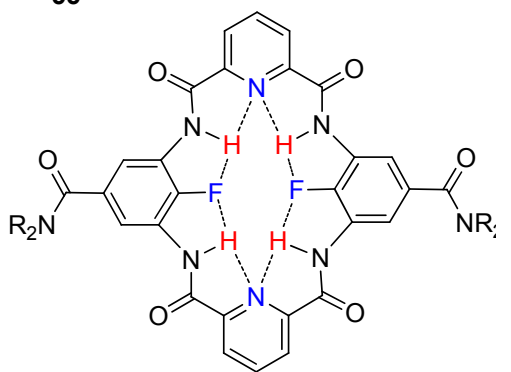

57

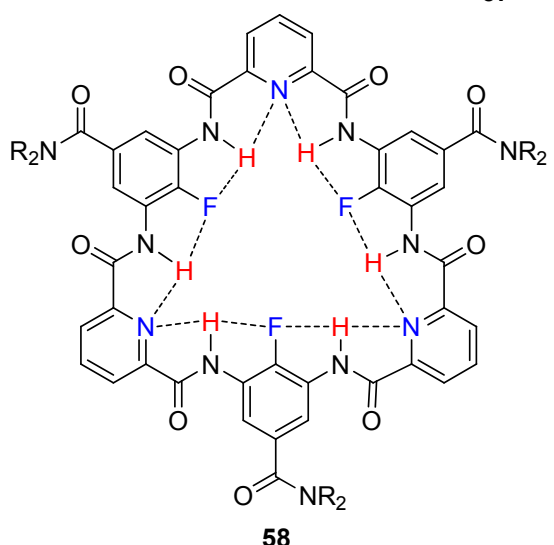

图 $17 \mathrm{~F} \cdots \mathrm{H} \cdots \mathrm{X}(\mathrm{X}=\mathrm{F}, \mathrm{N})$ 型分子内三中心氢键诱导形成的 大环

Figure 17 Macrocycles induced by the $\mathrm{F} \cdots \mathrm{H} \cdots \mathrm{X}(\mathrm{X}=\mathrm{F}, \mathrm{N})$ typed intramolecular three-center hydrogen bond
Hamilton 等 ${ }^{[77]}$ 以 5-氨基-6-烷氧基吡啶酸甲酯为原 料，合成了一类基于三聚芳酰胺折叠体的新型 $\alpha$-螺旋模 拟物 59(图 18). 通过 ${ }^{1} \mathrm{H}$ NMR 和理论计算模型证实了这 些分子在氯仿和二甲基亚砜中均存在 $\mathrm{O} \cdots \mathrm{H} \cdots \mathrm{O}$ 型分子 内三中心氢键. 硝基衍生物 $59 \mathrm{f}$ 的晶体结构进一步表明, 三聚芳酰胺主链是平面的, 所有异丙氧基侧链都从主链 的一侧投射出来. 同样, 由于三中心氢键的引导以及吡 啶环中 $\mathrm{N}-\mathrm{C}$ 键相对于 $\mathrm{C}-\mathrm{C}$ 键的收缩, 主链略微弯曲.

黎占亭等 ${ }^{[78]}$ 采用适当修饰的对苯二胺和对苯二甲 酸为基本原料，设计合成了一类新的具有 $\mathrm{O} \cdots \mathrm{H} \cdot \mathrm{O}$ 型 分子内三中心氢键的芳香低聚酰胺 $(60 \sim 63$, 图 18). 在 较强的三中心氢键作用限制下，这类新的低聚物自组装 成高度稳定的直的平面型分子带. 其中, 三聚物 60 和 61 的晶体结构表明, 所有酰胺质子都参与形成了六元 环分子内三中心氢键. 这种三中心氢键的存在, 还经过 ${ }^{1} \mathrm{H}$ NMR、IR 和 UV-vis 光谱等实验结果证实. 此外, 酯 基还可以被烷氧基取代，形成由五元环和六元环组成的 分子内三中心氢键(化合物 64, 图 18) ${ }^{[79]}$.

如果用硫醚基团修饰芳环，则可以合成得到具有 $\mathrm{S} \cdots \mathrm{H} \cdots \mathrm{X}(\mathrm{X}=\mathrm{N}, \mathrm{O})$ 型分子内三中心氢键的芳香低聚酰 胺类刚性拓展结构. Tew 等 ${ }^{[31]}$ 以 4,6-二羧基嘧啶和硫醚 基团修饰的间苯二胺衍生物为基本原料，通过缩合反 应，合成得到具有优异抗菌活性的两亲性芳香低聚酰胺 65a 和 $65 b$ (图 19). $S \cdots H \cdot \cdots \mathrm{N}$ 型分子内三中心氢键的形 成，不仅促使该低聚物形成一种扩展的刚性构象，而且 增加了其抗菌活性. 基于类似思想, DeGrado 等 ${ }^{[32]}$ 设计 合成了具有 $\mathrm{S} \cdots \mathrm{H} \cdots \mathrm{O}$ 型分子内三中心氢键的芳香低聚 酰胺折叠体 66(图 19). 在骨架的另一侧, 同时观察到芳 基质子和酰胺基氧原子之间存在着分子内氢键. 在这些 氢键相互作用的驱使和诱导下, 芳香低聚酰胺折叠体呈 现完全平面构象.

具有直线型拓展结构的分子, 可以通过分子间的非 共价作用力边对边地聚集形成分子拉链 ${ }^{[80-81]}$. 袁立华 等 ${ }^{[82-83]}$ 用酰亚胺或艮基为连接单元，合成了一系列具有 不同的多重氢键结合位点的分子链. 其中, 酰亚胺部分 能形成由两个六元环组成的分子内三中心氢键, 使其较 好地保持线性拓展结构. 这些分子链在非极性溶剂中能 配对形成同源或异源的多重氢键自组装体系. 例如化合 物 67 能在氯仿中自组装形成稳定的分子拉链 $67 \cdot 67$

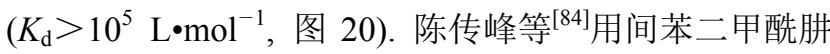
和乙基丙二酸单酯为主要原料, 合成了具有多重氢键结 合位点的寡聚酰肼类化合物 68 . 通过分子力学计算表 明, 肼基中 $\mathrm{N}-\mathrm{H}$ 除了能与苯环上烷氧基中的氧原子形 成六元环分子内氢键外, 还能与邻近的丙二酰中羰基氧 原子形成一个五元环的分子内氢键, 共同组成 $\mathrm{O} \cdots \mathrm{H} \cdot \cdots$ 


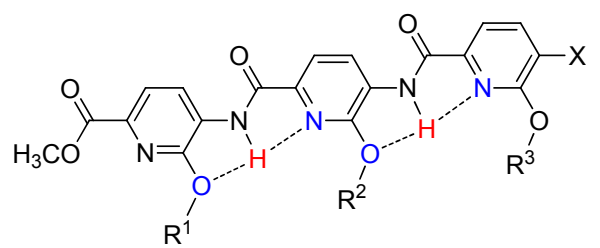

59a: $R^{1}, R^{2}, R^{3}=M e ; X=\mathrm{NH}_{2}$ 59b: $\mathrm{R}^{1}, \mathrm{R}^{2}, \mathrm{R}^{3}=i-\mathrm{Pr} ; \mathrm{X}=\mathrm{NH}_{2}$ 59c: $R^{1}, R^{2}, R^{3}=B n ; X=N_{2}$ 59d: $\mathrm{R}^{1}, \mathrm{R}^{3}=i-\mathrm{Pr} ; \mathrm{R}^{2}=\mathrm{Me} ; \mathrm{X}=\mathrm{NH}_{2}$ 59e: $\mathrm{R}^{1}, \mathrm{R}^{2}=\mathrm{Bn} ; \mathrm{R}^{3}=i-\mathrm{Pr} ; \mathrm{X}=\mathrm{NH}_{2}$ 59f: $\mathrm{R}^{1}, \mathrm{R}^{2}, \mathrm{R}^{3}=i-\mathrm{Pr} ; \mathrm{X}=\mathrm{NO}_{2}$<smiles>CCOC(=O)c1cc2oc3ccccc3c(=O)n(C)c3c(C(=O)OCC)c2cc1N3C(=O)c1ccccc1OC</smiles><smiles>CCOC(=O)c1ccccc1N(C)C(=O)c1cc2c(cc1OC)C(=O)N1c3ccccc3C(=O)OC1OC2C</smiles>

61

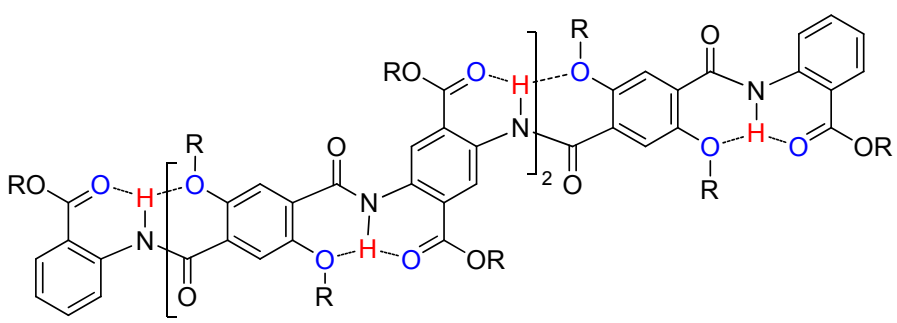

$63 \mathrm{R}=n-\mathrm{C}_{6} \mathrm{H}_{13}$<smiles></smiles><smiles></smiles>

64

图 18 分子内三中心氢键诱导形成的拓展结构

Figure 18 Extended structures induced by intramolecular three-center hydrogen bond

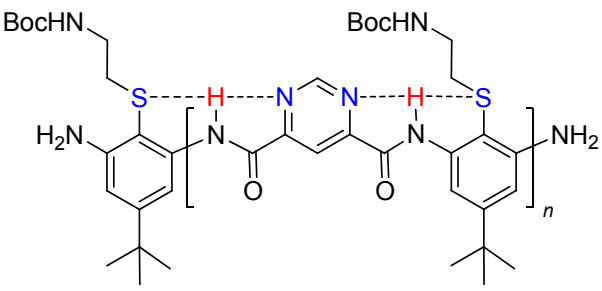

65a: $n=1 ; 65 \mathbf{b}: n=2$

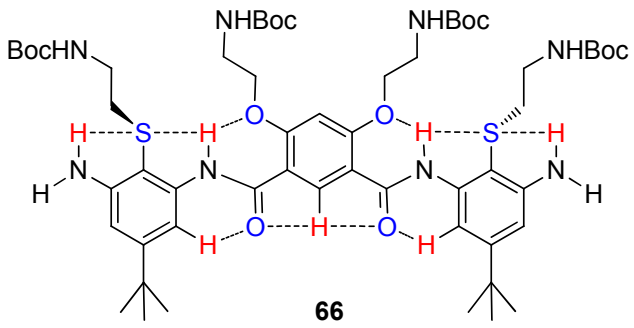

图 19 基于 $\mathrm{S} \cdots \mathrm{H} \cdots \mathrm{X}(\mathrm{X}=\mathrm{N} 、 \mathrm{O})$ 型分子内三中心氢键的拓展 结构

Figure 19 Extended structure induced by $S \cdots H \cdots X(X=N, O)$ type intramolecular three-center hydrogen bond

$\mathrm{O}$ 型分子内三中心氢键, 使分子的刚性进一步加强, 能 够较好地保持线性拓展结构. 在非极性溶剂中, 化合物 68 可以配对形成多重氢键自组装体系 $68 \cdot 68$ (图 20).

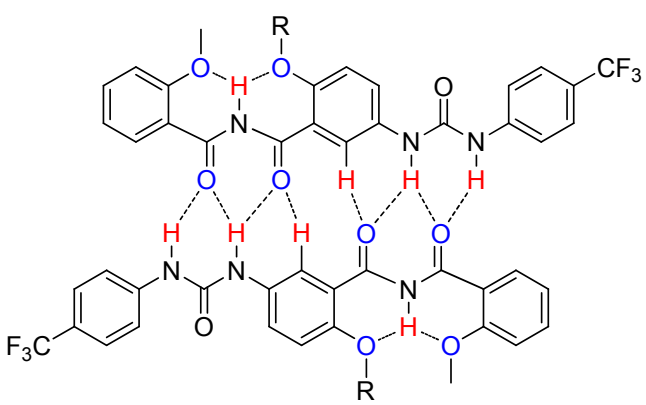

67.67 R $=\mathrm{CH}_{2} \mathrm{CH}_{2} \mathrm{CH}\left(\mathrm{CH}_{3}\right)_{2}$

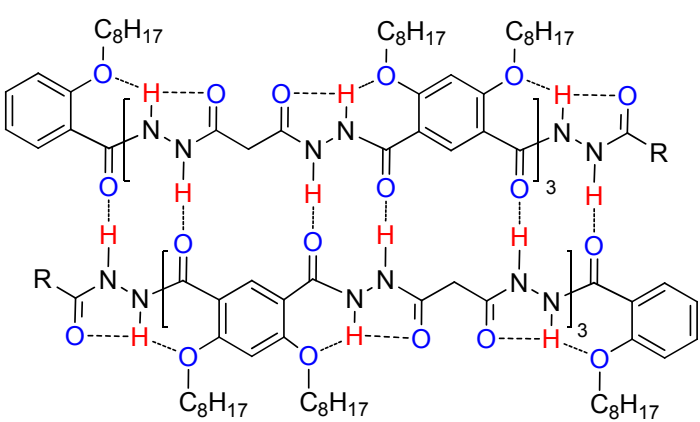

68a.68a $\mathrm{R}=\mathrm{CH}_{3}$ 68b 68b R $=\mathrm{OC}\left(\mathrm{CH}_{3}\right)_{3}$

图 20 基于分子内三中心氢键的分子拉链

Figure 20 Molecular duplexes based on intramolecular threecenter hydrogen bond 


\section{3 基于分子内三中心氢键超分子组装体系的应} 用

分子内三中心氢键是一种极为有效和十分可靠的 控制分子构象的手段, 在超分子自组装领域有着重要的 应用.近年来，人们基于分子内三中心氢键设计合成了 各种各样的超分子组装体, 例如大环化合物、折叠体、 含孔螺旋化合物、直线型及其他扩展构型分子等. 这些 超分子组装体通常具有刚性较强、空腔尺寸可调、侧链 易修饰等优点, 被广泛应用于催化反应、分子和离子识 别、离子通道、光学和电子器件、软物质材料、分子机 器等领域.

\section{1 促进有机反应}

在分子内三中心氢键存在的情况下, 寡聚物通常呈 现出稳定的折叠构象. 通过合理的设计, 这种刚性骨架 的预组织作用可以促进某些有机反应. 例如, 当折叠骨 架的两端连接有反应所需的基团时, 刚性骨架的预组织 作用可促进这些基团发生反应形成大环化合物. 环化反 应机理可以是一锅法, 也可以是分步反应 ${ }^{[1]}$. 基于此种 合成策略, 黎占亭等 ${ }^{[85]}$ 设计合成了末端分别含有两个 醛基和氨基的三聚物 69 和 70. 由于分子内三中心氢键 的预组织作用, 三聚物 69 和 70 均呈现稳定的折叠构象. 在 $\mathrm{CHCl}_{3} / \mathrm{DMSO}(4: 1)$ 中室温反应 $5 \mathrm{~h}$, 三聚物 69 和 70 可以通过缩合反应几乎定量地转化为大环化合物 71(产 率 $\geqslant 95 \%$, Scheme 1). ${ }^{1} \mathrm{H}$ NMR 研究表明, 反应首先生成 复杂的产物, 由于亚胺键的可逆性, 逐渐转化为最稳定 的大环化合物 71. 此外, 黎占亭等还利用分子内三中心 氢键对构象的预组织作用, 通过 1,3-偶极环加成反

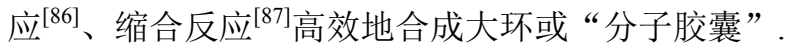

除了促进环化反应外, 分子内三中心氢键的预组织 作用还能促进很多其他反应，例如氧化反应、水解反应 等. Huc 等 ${ }^{[88}$ 以 2,6-二氨基吡啶和 2,6-吡啶二甲酸为单 体, 设计合成了低聚酰胺 72a 和 72b. 研究发现, $m$ CPBA 可以将 72a 和 72b 末端吡啶单元选择性氧化为 73a 和 73b (Scheme 2). 核磁检测结果显示 $\left(\mathrm{CDCl}_{3}\right.$, $\left.25{ }^{\circ} \mathrm{C}\right), 72 \mathrm{a}$ 和 72b 的氧化速度明显快于对照化合物. 此 外，氧化反应只发生在末端的吡啶单元. 由于这些低聚 物形成双螺旋二聚体, 其选择性被认为是由于螺旋构象 中的偶极相互作用以及氧化剂在双螺旋极性空腔中的 预分离, 但具体机制尚不清楚. 黎占亭等 ${ }^{[89]}$, 设计并合 成了主链末端为 2-甲氧基-3-硝基苯甲酰胺单元的低聚 芳香酰胺折叠体 74a 74d. 低聚物 74a 74d 的折叠体 的主链类似于刚性球体, 能够与 $\mathrm{Li}^{+} 、 \mathrm{Na}^{+} 、 \mathrm{~K}^{+}$形成络合 物. 在 $60 \sim 90{ }^{\circ} \mathrm{C}$ 的二氧六环-水 $(V: V=4: 1)$ 中, 2-甲 氧基-3-硝基苯甲酰胺单元的甲氧基能很快的水解为羟 基, 生成低聚芳香酰胺折叠体 75a $\sim 75 d$ (Scheme 2). 动 力学研究表明, 较长的折叠体通常表现出增强的加速效 应, 且 $\mathrm{LiOH}$ 表现出最高的反应活性. 该研究结果还表 明, 即使在高极性的热水介质中, 分子内三中心氢键仍 然能够诱导结构匹配的低聚物产生预组织的刚性构象.

含有特殊配位基团的低聚芳香酰胺折叠体能与某 些金属离子形成稳定的络合物，并用于催化有机反应. 例如, 江华等 ${ }^{[00]}$ 以单手性喹啉低聚酰胺为原料, 设计合 成了一系列手性双膦配体 76. 双膦配体 76 在 $\mathrm{N} \cdots \mathrm{H} \cdots \mathrm{N}$ 型分子内三中心氢键的限制下形成稳定的折叠构象，能 与 $\mathrm{Rh}(\mathrm{cod})_{2} \mathrm{BF}_{4}$ 以 $1: 1$ 的化学计量比配位, 形成能应用 于 $\alpha$-脱氢氨基酸酯的不对称氢化反应的手性催化剂 76[Rh] (Scheme 3). 其中, 76b[Rh]获得了良好的转化率
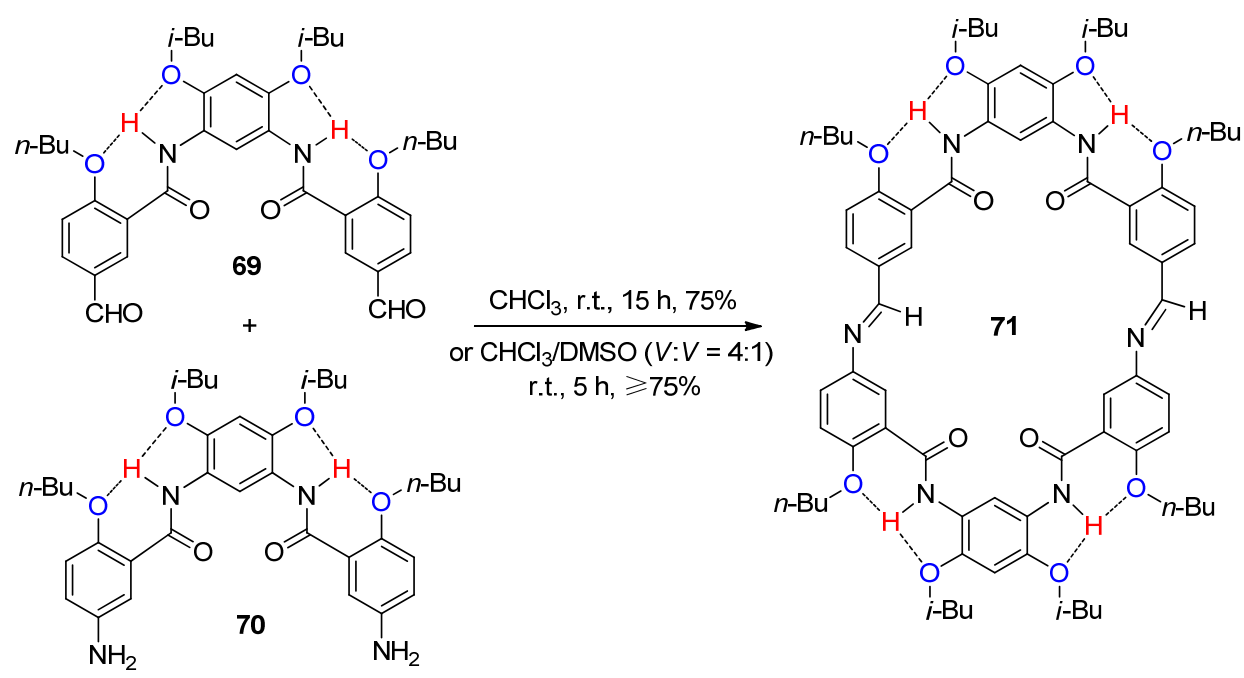

图式 1 分子内三中心氢键预组织作用促进缩合反应

Scheme 1 Condensation reaction promoted by the preorganization of intramolecular three-center hydrogen bond 
<smiles>[R]C(=O)Nc1cccc(NC(=O)c2cc([R])cc(C(=O)Nc3cccc(NC(=O)c4cc([R])cc(C(=O)C(C)(C)Nc5cccc(NC([R])=O)n5)n4)n3)n2)n1</smiles>

72a: $n=2, \mathrm{R}^{1}=n-\mathrm{C}_{9} \mathrm{H}_{19}, \mathrm{R}^{2}=\mathrm{OC}_{10} \mathrm{H}_{21} ; 72 \mathrm{~b}: n=2, \mathrm{R}^{1}=\mathrm{OBn}, \mathrm{R}^{2}=\mathrm{H} \quad \mathrm{R}^{2}$

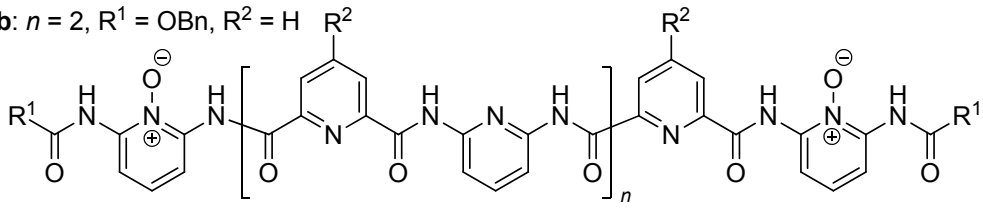

73a: $n=2, \mathrm{R}^{1}=n-\mathrm{C}_{9} \mathrm{H}_{19}, \mathrm{R}^{2}=\mathrm{OC}_{10} \mathrm{H}_{21} ; 73 \mathrm{~b}: n=2, \mathrm{R}^{1}=\mathrm{OBn}, \mathrm{R}^{2}=\mathrm{H}$

(b)<smiles>COC1=C2C=C(C)C=C(c3c(C)cc(C)cc31)N(c1ccccc1OC)C2=O</smiles>

$\underset{\triangle}{\stackrel{\mathrm{MOH}(\mathrm{M}=\mathrm{Li}, \mathrm{Na}, \mathrm{K})}{\mathrm{H} \text { O-dioxane }(V: V=1: 4)}}$

74a: $n=0 ; 74 b: n=1 ; 74 c: n=2 ; 74 d: n=3$

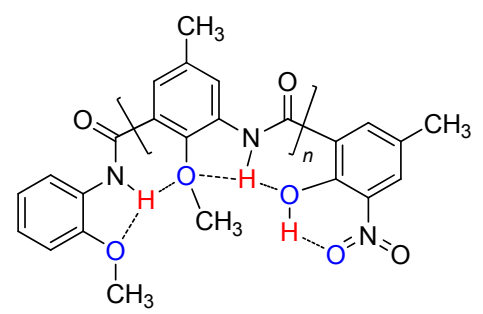

75a: $n=0 ; 75 b: n=1 ; 75 c: n=2 ; 75 d: n=3$

图式 2 分子内三中心氢键预组织作用促进有机反应: (a)氧化反应, (b)水解反应

Scheme 2 Reactions promoted by the preorganization of intramolecular three-center hydrogen bond: (a) oxidation reaction, (b) hydrolysis reaction

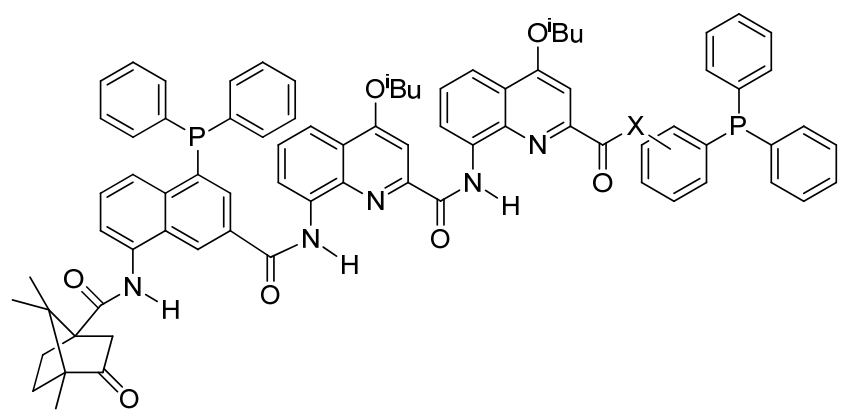<smiles>COC(=O)/C(=C\c1ccccc1)NC(C)=O</smiles>

76a: $\mathrm{X}=m-\mathrm{O}, 76 \mathbf{b}: \mathrm{X}=m-\mathrm{NH}, 76 \mathbf{c}: \mathrm{X}=\mathrm{o}-\mathrm{NH}, 76 \mathbf{d}: \mathrm{X}=p-\mathrm{NH}$

图式 3 手性催化剂 76[Rh]催化的不对称氢化反应

Scheme 3 Asymmetric hydrogenation catalysted by $76[\mathrm{Rh}]$

(>98\%)以及中等的对映选择性(49\%).

\section{2 离子和分子识别}

分子内三中心氢键诱导形成的大环、折叠体等含孔 刚性结构, 具有长度易于调节, 主链和侧链易于通过离 散的官能团进行修饰等优点, 被广泛用于离子和分子识 别.

曾华强等 ${ }^{[91]}$ 设计合成了具有不同外侧取代基以及 内侧甲氧基个数的五聚芳酰胺大环 77～79(图 21), 并系 统地研究了它们对碱金属离子识别行为. 这些化合物的 内腔至少包含一个酚羟基, 能够在脱质子时与金属离子 发生相互作用. 此外, 内腔中的甲氧基具有较大空间位 阻和疏水性, 能对 77 79 的阳离子结合电位进行微调. 在去质子化作用下, 通过等温量热滴定法(ITC)详细研
究了这些大环主体阴离子与不同碱金属离子的结合能 力. 研究发现, 通过改变苯环外侧取代基的结构以及内 侧甲氧基的个数, 能够系统地调节内部特性(有效空腔 尺寸、空间拥挤性、疏水性), 使之对碱金属离子 $\left(\mathrm{Li}^{+}\right.$、 $\mathrm{Na}^{+} 、 \mathrm{~K}^{+} 、 \mathrm{Rb}^{+} 、 \mathrm{Cs}^{+}$)有不同的结合力.

袁立华等 ${ }^{[22-95]}$ 对寡聚芳酰胺大环的离子、分子识别 性能进行了详细研究. 例如，袁立华等 ${ }^{[94]}$ 设计合成了缺 少两组分子内三中心氢键的六聚芳酰胺大环 80 (图 22). 研究发现, 它们在氯仿中能强烈结合二丁基氯化铵 $(>$ $\left.10^{5} \mathrm{~L} \cdot \mathrm{mol}^{-1}\right)$, 从而形成[2]类轮烷结构. 其中, 酰胺键是 有效识别离子对的唯一官能团. 袁立华等 ${ }^{[95}$ 研究还发 现，六聚芳酰胺大环 81 能与咪唑盐类分子形成主客体 复合物离子液体(图 22). 通过改变 $N$-取代基或者抗 


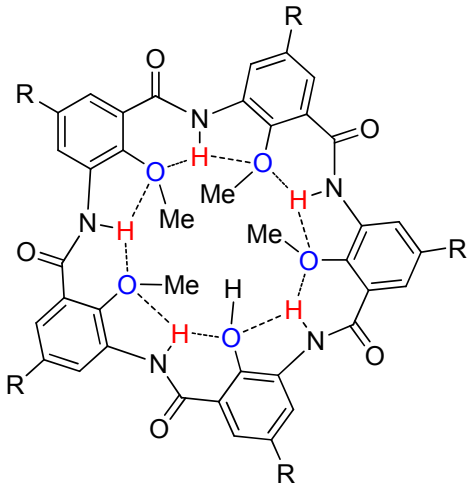

77a: $\mathrm{R}=\mathrm{H} ; \mathbf{7 7 b}: \mathrm{R}=\mathrm{O} n-\mathrm{C}_{8} \mathrm{H}_{17}$

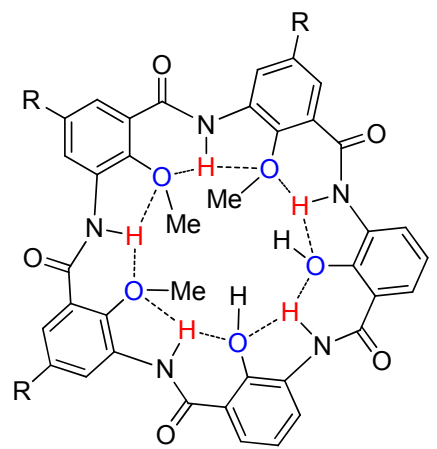

78a: $\mathrm{R}=\mathrm{H} ; \mathbf{7 8 b}: \mathrm{R}=\mathrm{On}-\mathrm{C}_{8} \mathrm{H}_{17}$

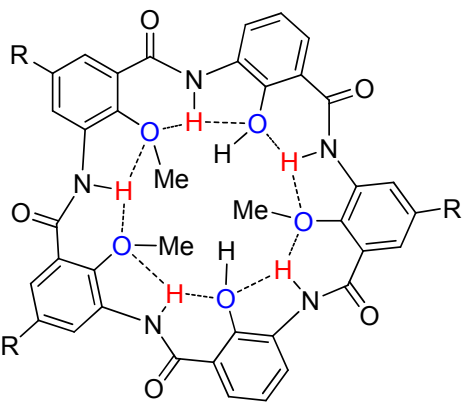

79a: $\mathrm{R}=\mathrm{H} ; 79 \mathrm{~b}: \mathrm{R}=\mathrm{On}-\mathrm{C}_{8} \mathrm{H}_{17}$

图 21 五聚芳酰胺大环 77 79 的结构

Figure 21 Structures of pentameric arylamide macrocycles $77 \sim 79$

衡的阴离子, 可以调节它们之间结合力. 此外, 通过改 变体系的浓度、竞争离子以及体系的酸碱度, 可以实现 对这种复合物离子液体的临界溶液温度的精准控制. 更 为有趣的是, 大环分子 81 与碘离子咪唑盐形成的主客 体复合物可以分离两种不同的有机染料, 在分离科学中 具有广阔的应用前景.

除大环化合物外，寡聚芳酰胺折叠体也能用于离子 或分子识别 ${ }^{[96-98]}$. 例如, 黎占亭等 ${ }^{[97]}$ 以 5-甲基-2-差基苯 甲酸为起始原料, 经酯化、硝化、还原、水解、缩合等 反应，合成了三中心氢键处于分子骨架内侧的寡聚芳酰 胺 $82 \mathrm{a} \sim 82 \mathrm{e}$ (图 23). 在分子内三中心氢键的限制作用

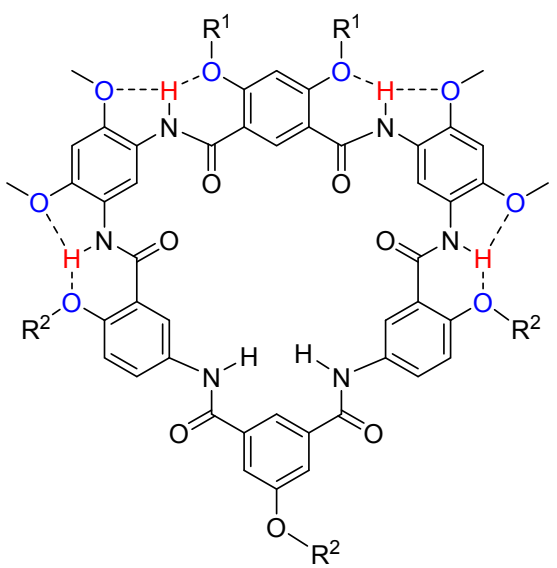

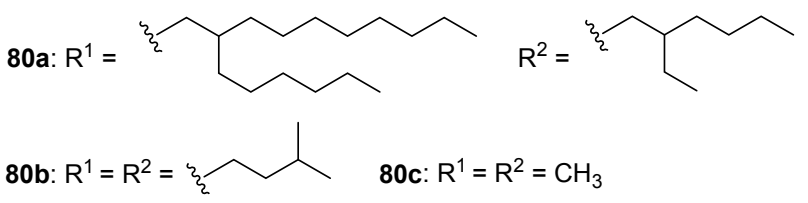

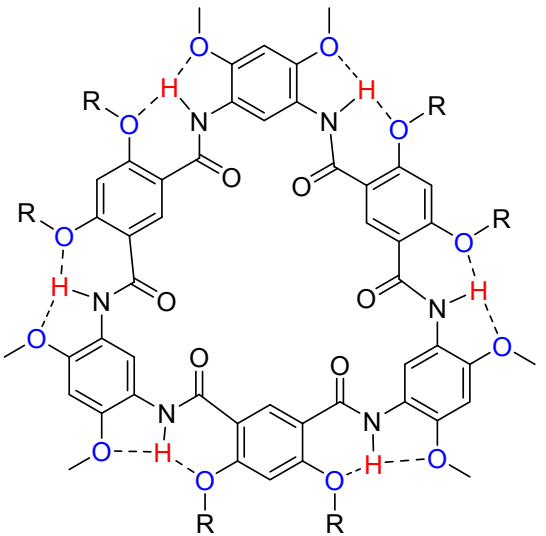

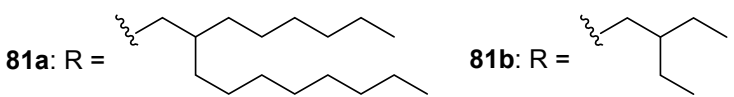

81c: $\mathrm{R}=\mathrm{CH}_{3}$

图 22 六聚芳酰胺大环 80 和 81 的结构

Figure 22 Structures of hexameric arylamide macrocycles $\mathbf{8 0}$ and $\mathbf{8 1}$

下，寡聚芳香酰胺形成稳定的折叠构象. 分子力学计算 结果表明，这类新型的折叠体含有一个直径小于 $1 \mathrm{~nm}$ 的刚性空腔. 苂光和 ${ }^{1} \mathrm{H}$ NMR 实验结果表明, 它们在氯 仿中对烷基铵离子具有较强的结合作用. 其中，五聚体 82d 具有最大的结合能力 $\left(K_{\mathrm{a}}=360 \mathrm{~L} \cdot \mathrm{mol}^{-1}, \mathrm{CDCl}_{3}\right)$. 江 华等 ${ }^{[98]}$ 以喹啉低聚酰胺折叠体为原料, 设计合成了两 个末端苯环上含有 $\mathrm{C}-\mathrm{F}$ 键的五聚体化合物 83 和 84 , 它 们可用于手性胺、二胺、氨基醇和 $\alpha$-氨基酸酯的对映体 过量测定和绝对构型测定. 当手性分析物与 83 中的 $\mathrm{C}-\mathrm{F}$ 键发生 $N$-亲核取代反应时, 83 的手性诱导被原位 触发. 由于喹啉生色团区域的 CD 振幅与手性分析物的 $e e$ 值呈线性相关，化合物 83 可用于手性分析物的 $e e$ 值 
测定. 在 $\mathrm{C}$ 端手性基团的诱导下，化合物 84 形成具有单 一手性的螺旋结构. 当 $\mathrm{N}$ 端手性分子原位触发的手性诱 导与化合物 84 原诱导匹配时, 则所得到折叠体的 CD 振 幅和 $d e$ 值都会增加; 如果不匹配, $\mathrm{CD}$ 振幅和 $d e$ 值会减 小. 因此, 在已知化合物 $84 \mathrm{C}$-端手性基团的手性性质 的前提下, 可以通过 $\mathrm{CD}$ 振幅和 $d e$ 值的变化测定手性分 析物的绝对构型.

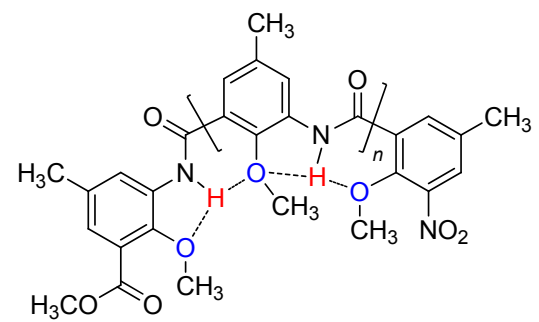

82a: $n=0 ; 82 \mathrm{~b}: n=1 ; 82 \mathrm{c}: n=2 ; 82 \mathrm{~d}: n=3 ; \mathbf{8 2 e}: n=4$<smiles>CCCCOc1cc(C(=O)C(C)(C)OC)nc2c(NC(C)(C)C(=O)c3cc(OCC)c4ccc([N+](=O)[O-])c(F)c4n3)cccc12</smiles>

83<smiles>CCCCOc1cc(C(=O)N[C@H](C)c2ccccc2)nc2c(NC(C)(C)C(=O)c3cc(OCC)c4ccc([N+](=O)[O-])c(F)c4n3)cccc12</smiles>

84

图 23 葟聚芳酰胺折叠体 $82 \sim 84$ 的分子结构

Figure 23 Molecular structures of aromatic oligoamide foldamers $82 \sim 84$

\section{3 跨膜通道}

人们在研究生物跨膜通道的基础上, 利用非天然分 子模仿并制备了许多人工跨膜通道, 用于输送生物活性 的离子、小分子及生物大分子等, 其中具有孔隙结构的 刚性寡聚芳酰胺大环以及折叠体的自组装是构筑跨膜 通道最常用的一种方法. 龚兵等 ${ }^{[99]}$ 设计合成了基于分 子内三中心氢键的刚性芳酰胺大环 85 , 其能够在脂质 双分子层中自组装成离子通道, 且该通道对 $\mathrm{Na}^{+}$和 $\mathrm{K}^{+}$ 具有良好的传输性能(图 24). 在此基础上, 龚兵等 ${ }^{[100]}$ 设 计合成了具有相同的杂化主链和相同的侧链, 同时具有 不同内腔的刚性大环 86a $\sim 86 d$ (图 24). ${ }^{1} \mathrm{H}$ NMR、苂光光 谱和原子力显微镜等多种研究结果显示, 大环 $\mathbf{8 6 a} \sim$ 86d 能聚集形成结构相似且具有亚纳米孔道的管状自组 装结构. 基于脂质囊泡苂光淬灭动力学测试(vesiclebased stopped-flow kinetic assay)和平面脂双层单通道电 生理方法(single-channel electrophysiology with planar lipid bilayers)的研究表明, 内腔中不同功能基团的存在 导致相应的自组装纳米管展现了极为不同的离子传输 特性. 含有氨基和甲基内腔基团的自组装结构孔穴具有 不可思议的、明显的排斥质子但可通过较大离子的传输 行为. 内腔基团可使所形成的跨膜传输孔道具有不同程 度的正电位，导致不同的通道具有对阳离子和阴离子不 同的传输能力.

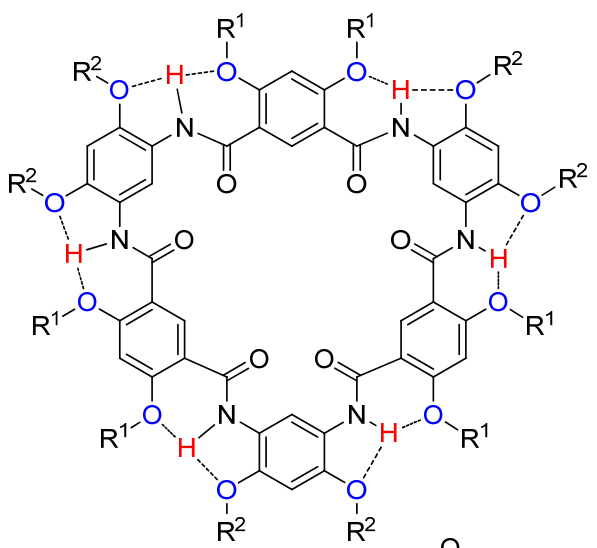

85a: $\mathrm{R}^{1}=n-\mathrm{C}_{8} \mathrm{H}_{17}, \mathrm{R}^{2}=\mathrm{CH}_{3} ; 85 \mathrm{~b}: \mathrm{R}^{1}=$ s $^{5} \mathrm{OC}_{2} \mathrm{H}_{5}, \mathrm{R}^{2}=\mathrm{CH}_{3}$ 85c: $\mathrm{R}^{1}=s^{5} \mathrm{OO}_{3}, \mathrm{R}^{2}=\mathrm{CH}_{3} ; 85 \mathrm{~d}: \mathrm{R}^{1}=s^{s}$ $\mathrm{R}^{2}=\mathrm{CH}_{3} ; 85 e: \mathrm{R}^{1}=\mathrm{CH}_{3}, \mathrm{R}^{2}=s^{5}$

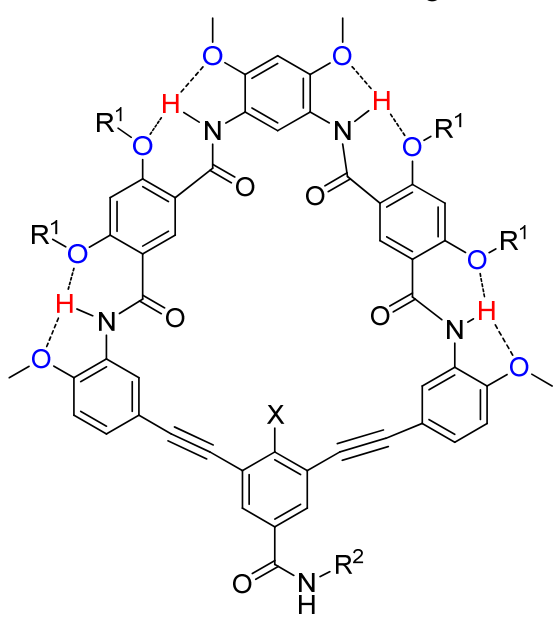

86a: $X=H ; 86 b: X=\mathrm{CH}_{3} ; 86 c: X=F ; 86 d: X=\mathrm{NH}_{2}$<smiles>[R]=C=CC(C)C(=O)OCCCC</smiles>

图 24 大环化合物 85 和 86 的结构

Figure 24 Structures of macrocycles 85 and 86

在基于具有孔隙结构的刚性大环以及折叠体构筑 人工离子通道领域, 黎占亭等 ${ }^{[101-102]}$ 也做了很多研究. 例如黎占亭等 ${ }^{[101]}$ 设计并合成了一系列新的带有苯丙氨 酸三肽侧链的芳酰肼低聚物 87 和聚合物 88(图 25). 在 骨架内外两组 $\mathrm{O} \cdots \mathrm{H} \cdots \mathrm{O}$ 型三中心氢键的限制和驱使下, 
这些芳酰肼低聚物和聚合物形成稳定的螺旋结构. 它们 可以插入脂质双分子层中形成单分子离子通道, 可以介 导阳离子的跨膜传输. 研究结果表明, 最长的寡聚和聚 合螺旋通道显示出的 $\mathrm{NH}_{4}{ }^{+} / \mathrm{K}^{+}$选择性高于天然短杆菌肽 $\mathrm{A}$ 的选择性, 而短螺旋通道对 $\mathrm{Tl}^{+}$的转运可以获得与短 杆菌肽 A 接近的效率. 黎占亭等 ${ }^{[102]}$ 研究还发现, 含有 苯丙氨酸三肽侧链的刚性芳酰肼大环 89 和 90(图 25)也 具有类似性质.

\section{4 分子机器}

具有环状互锁结构的轮烷和类轮烷分子是分子机 器的基本模型. 在外界刺激作用下, 轮烷或类轮烷超分 子体系能够沿其轴向产生往返运动, 在分子开关、分子 器件、分子逻辑门、药物释放、信息存储等方面具有很 大的应用前景.

与伸展态相比, 氢键型折叠低聚物具有更大的表观 尺寸，折叠态与伸展态之间的可逆转换将破坏或恢复分
子内氢键. 基于氢键型折叠体的此种性能, 黎占亭 等 ${ }^{[103-104]}$ 设计合成了含有氢键型折叠体片段的[2]轮烷

91a 和 91b, 它们能与由环双(百草枯一对-苯撑)组成的联 吡啶鎓盐单元 $\left(\mathrm{CBPQT}^{4+}\right)$ 形成具有氧化还原响应的主客 体系统(图 26). 其中, 氢键型折叠体片段被用于分离富 电子的四硫富瓦烯(TTF)和 1,5-二氧萘(DNP)单元. 但 是, 一旦折叠状态通过分子内氢键断裂而打开到伸展状 态, $\mathrm{CBPQT}^{4+}$ 环就可能在线性组分上穿梭. 由于 $\mathrm{TTF}$ 实 质上比 DNP 更富电子，当在中性态时, $\mathrm{CBPQT}^{4+}$ 环专一 地环绕在 TTF 单元上面. 当 $\mathrm{TTF}$ 被氧化成阳离子自由基 $\left(\mathrm{TTF}^{+}\right)$或二价阳离子 $\left(\mathrm{TTF}^{2+}\right)$ 时, $\mathrm{CBPQT}^{4+}$ 环被排斥滑 过氢键折叠体片段而环绕在 DNP 单元上. 当 $\mathrm{TTF}^{+}$或 $\mathrm{TTF}^{2+}$ 被还原为 $\mathrm{TTF}$ 时，将导致形成亚稳态构象 (metastable state co-conformation, MSCC). 于此同时, $\mathrm{CBPQT}^{4+}$ 环后移滑过氢键折叠体片段再次包围 TTF 单 元，形成基态构象(ground-state co-conformation, GSCC).

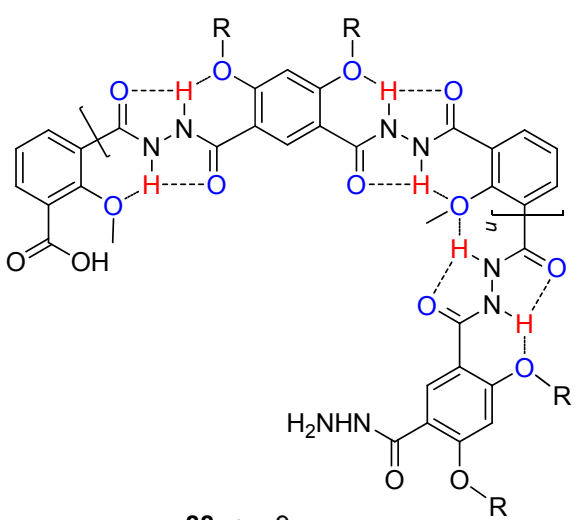

88: $n \approx 9$

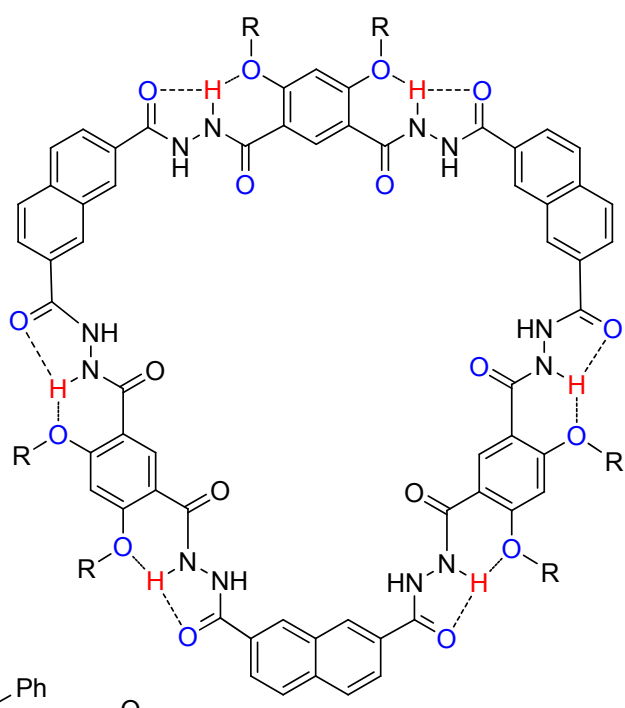

90 


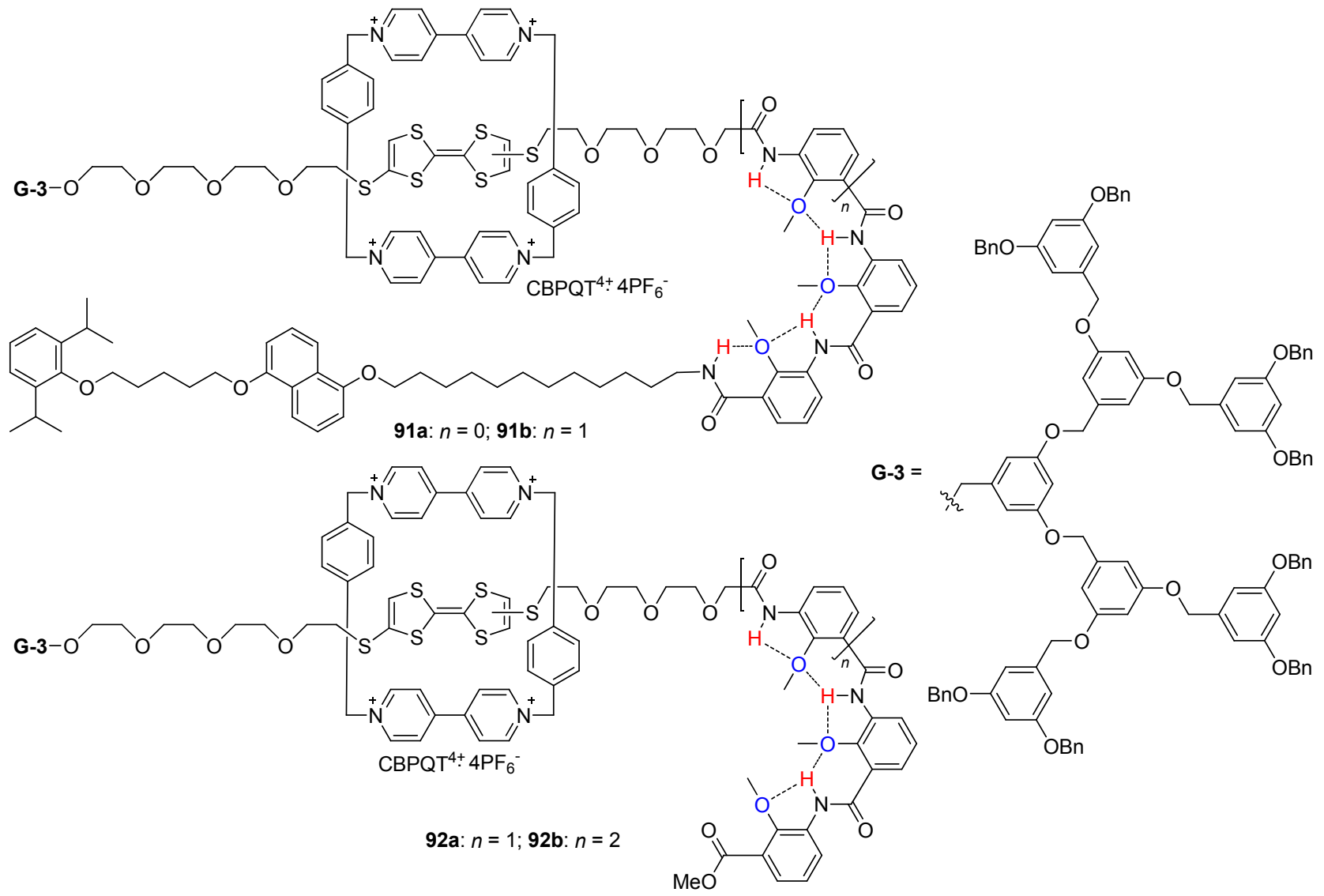

图 26 化合物 91 和 92 的结构

Figure 26 Structures of compounds 91 and 92

通过记录在 $805 \mathrm{~nm}$ 处随时间变化的电荷转移吸收, 发 现在极性较低的氯仿中的穿梭半衰期远低于在乙腈中 的穿梭半衰期. 该研究结果表明, 在极性较低的介质中, 氢键折叠体片段将施加较大的空间屏障, 以阻止或抑制 $\mathrm{CBPQT}^{4+}$ 环在两个富电子的芳香单元之间的穿梭, 从而 使整个过程以可控的方式进行. 黎占亭等 ${ }^{[105]}$ 研究还发 现, 类 [2] 轮烷 92a 和 92b 在非极性溶剂中可以组装形成 具有与正常囊泡相似功能的反向单层囊泡(图 26). 该反 向单层囊泡不仅具有氧化还原响应性, 还能以可调控的 方式释放封装的染料.

江华和 Huc 等 ${ }^{[106-107]}$ 通过自组装的方式构建了基于
螺旋分子与线型分子主客体相互作用的分子机器，并在 分子水平上实现对其运动的调控. 例如，江华和 $\mathrm{Huc}$ 等 ${ }^{[106]}$ 报道了折叠体 93 对线性分子 94 的结合行为(图 27). 折叠体 93 可以自组装形成双螺旋结构. 加入线型 客体后, 双螺旋分解成单螺旋, 并与客体分子络合生成 结构新颖的螺旋衍生的 [2]轮烷. 一旦形成螺旋-线型分 子主客体络合物后, 螺旋分子就能够在线型分子上快速 运动而不发生离解. 溶液状态和晶体结构研究表明, 折 叠体 93a 和线型分子 94a 形成 $1: 1$ 络合物, 螺旋在两个 脂肪链站点之间切换. 对于线型分子 $94 \mathrm{~b}$, 它的二烷基 氨基段可以作为螺旋运动的另一个站点. 通过氨基质子<smiles>[X]C(=O)c1cc(O[14CH3])c2cc3c(O[18O])cc(C([Y])=O)nc3c(F)c2n1</smiles><smiles>[Y]CNCc1ccc2c(O[14CH3])cc(C(=O)Nc3cccc(NC(=O)c4cccc(C(=O)Nc5cccc(NC(=O)C(C)(C)C)n5)n4)n3)nc2c1F</smiles>

93a: $n=1 ; 93 b: n=2 ; 93 c: n=4$

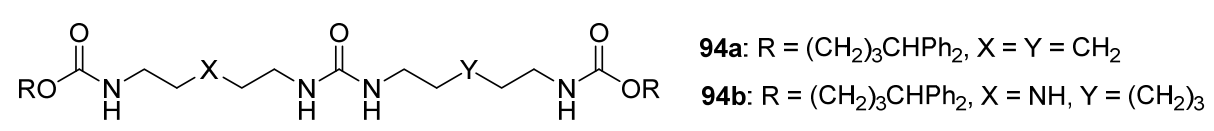

图 27 化合物 93 和 94 的结构

Figure 27 Structures of compounds 93 and 94 
化和去质子化, 可以实现对螺旋分子运动的调控. 该研 究工作所建立的模块设计和动态组装方法为设计新型 多位点控制的超分子自组装体系开辟了新途径. 江华和 Huc 等 ${ }^{[107]}$ 研究还发现, 具有双螺旋结构的折叠体也可 以与线型分子构建此类轮烷分子机器.

\section{5 软物质材料}

因为拥有一个刚性的芳香内核以及可修饰的外围 侧链, 芳香低聚酰胺类折叠体、大环经常用于构筑凝胶、 液晶等软物质材料. 例如, 黎占亭等研究发现芳香低聚 酰肼折叠体具有凝胶化非极性和极性溶剂的能 力 $^{[108-110]}$. 此外, 黎占亭等 ${ }^{[111]}$ 还设计合成了末端用胆固 醇修饰的芳香低聚酰胺 95a 95j(图 28). 由于分子内三 中心氢键的限制, 芳香低聚酰胺 95a 95 j 具有线性拓 展构象. 研究结果表明, 在低温下, 更多和更长的烷氧 基链有助于液晶相的形成. 值得注意的是, 含有两个甲 氧基和四个十二烷氧基的芳香低聚酰胺 $95 \mathrm{~g}$, 在加热和 冷却循环中都显示出蓝红色的变化.

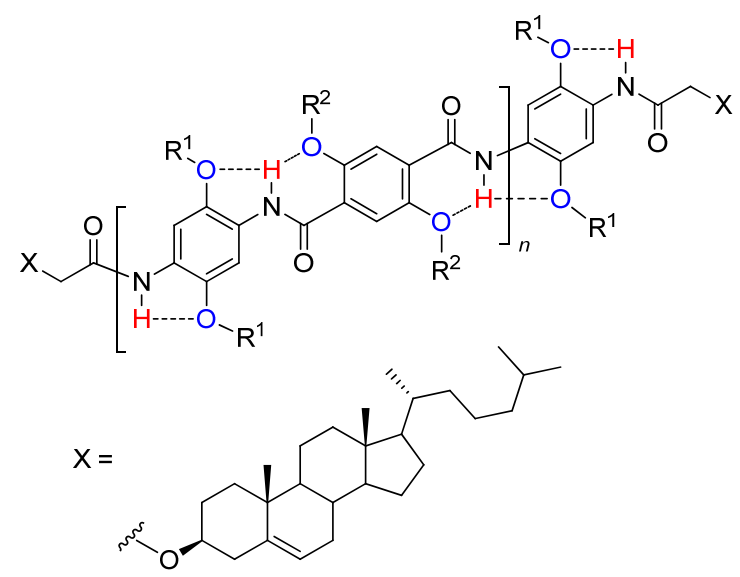

95a: $n=1, \mathrm{R}^{1}=\mathrm{R}^{2}=\mathrm{Me} ; 95 \mathrm{~b}: n=1, \mathrm{R}^{1}=\mathrm{Me}, \mathrm{R}^{2}=n-\mathrm{C}_{8} \mathrm{H}_{17} ; 95 \mathrm{c}$ : $n=1, \mathrm{R}^{1}=\mathrm{Me}, \mathrm{R}^{2}=n-\mathrm{C}_{12} \mathrm{H}_{25} ; 95 \mathrm{~d}: n=1, \mathrm{R}^{1}=n-\mathrm{C}_{8} \mathrm{H}_{17}, \mathrm{R}^{2}=\mathrm{Me}$; 95e: $n=1, \mathrm{R}^{1}=\mathrm{R}^{2}=n-\mathrm{C}_{8} \mathrm{H}_{17} ;$ 95f: $n=1, \mathrm{R}^{1}=n-\mathrm{C}_{8} \mathrm{H}_{17}, \mathrm{R}^{2}=$ $n-\mathrm{C}_{12} \mathrm{H}_{25} ;$ 95g: $n=1, \mathrm{R}^{1}=n-\mathrm{C}_{12} \mathrm{H}_{25}, \mathrm{R}^{2}=$ Me; 95h: $n=1, \mathrm{R}^{1}=$ $n-\mathrm{C}_{12} \mathrm{H}_{25}, \mathrm{R}^{2}=n-\mathrm{C}_{8} \mathrm{H}_{17} ; 95 \mathrm{i}: n=1, \mathrm{R}^{1}=\mathrm{R}^{2}=n-\mathrm{C}_{12} \mathrm{H}_{25} ; 95 \mathrm{j}: n=2$, $\mathrm{R}^{1}=\mathrm{R}^{2}=n-\mathrm{C}_{12} \mathrm{H}_{25}$

图 28 化合物 $\mathbf{9 5}$ 的结构

Figure 28 Structures of compounds 95

曾华强等 ${ }^{[112]}$ 设计以 2-氟-3-硝基苯甲酸为起始原料, 通过 15 步反应, 合成得到内腔含有氟原子的五聚芳酰 胺大环 96(图 29). 五聚芳酰胺大环 96 能使正己烷、乙 醚、乙酸乙酯和 1,4-二氧环己烷等有机溶剂凝胶化. 透 射电子显微镜(TEM)和 $X$ 射线衍射(XRD)研究表明, 它 们的凝胶网络中含有三维缠结的纳米纤维, 这些纤维是 由一维聚集体的柱间缔合形成的, 并通过晶间氢键和芳 香族堆积得到稳定.

袁利华等在基于芳香低聚酰胺折叠体 ${ }^{[113]}$ 、大环 ${ }^{[114]}$

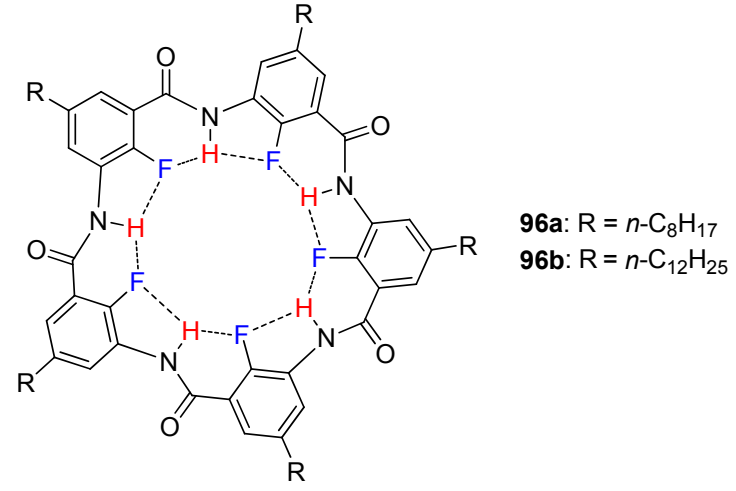

图 29 大环化合物 96 的结构

Figure 29 Structures of macrocycles 96

构筑液晶领域也做了很多研究. 例如，袁利华等 ${ }^{[114]}$ 设 计合成了六聚芳酰胺大环 $97 \mathbf{a} \sim 97 \mathrm{e}$ ，它们在相当宽的 温度范围内(包括室温)产生稳定的层状、盘状向列相、 六边形和矩形中间相的能力(图 30). 此外, 六聚芳酰胺 大环 97a 97e 在超分子主-客体相互作用 $(\mathrm{H}-\mathrm{G})$ 的调节 下, 表现出从层状到六方柱状的不寻常的中间相转变. 这种基于有机客体与大环空腔的主一客体相互作用触发 的相变, 为液晶材料的性能调控提供了一种新的策略. 通过对大环外部的进一步结构变化, 有望创造出具有新 的热反应和化学反应性的新型液晶材料.

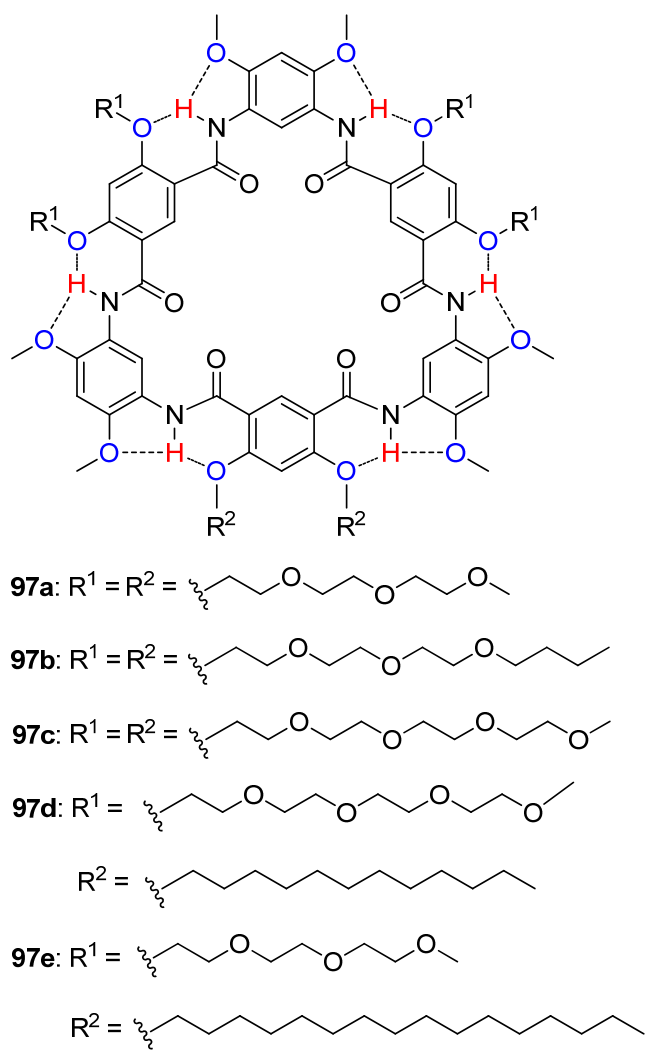

图 30 大环化合物 97 的结构

Figure 30 Structures of macrocycles 97 


\section{4 总结与展望}

分子内三中心氢键是一种极为有效和十分可靠的 控制分子构象的手段, 近年来在这一领域的研究已取得 了十分重要的进展. 人们基于其构建了各种各样结构美 妙的或具有一定功能的超分子组装体, 主要包括大环化 合物、折叠体和含孔螺旋化合物、分子拉链, 并被广泛 应用于促进有机反应、离子和分子识别、跨膜通道、分 子机器、软物质材料等领域.

尽管如此, 未来的研究工作仍面临许多困难与挑 战. 例如, 分子内三中心氢键超分子组装体系的高效合 成方法还有待于进一步发展; 对大环、折叠体的外围和 内部孔隙高度功能化修饰目前尚难以实现. 针对以上问 题，设计合成更简单、稳定性更好、适用范围更广的基 于分子内三中心氢键的超分子组装体, 并着力拓展其在 催化反应、液晶、分子分离技术、新型光学和电子器件 等领域的应用, 将是该领域研究的一个重要方向. 此外, 设计分子内三中心氢键与其他非共价作用(如 $\pi-\pi$ 堆积 作用、配位作用、离子键、供体-受体相互作用等)结合, 通过弱相互作用之间的协调和叠加, 形成能在生理条件 下稳定且具有特殊功能的仿生材料, 也是该研究领域极 具挑战性的课题. 这些问题的解决, 需要多学科的交叉 融合、协同创新.

\section{References}

[1] Pei, Q. J. Xinyang Normal Univ. (Nat. Sci. Ed.) 2018, 31, 160 (in Chinese). (裴强, 信阳师范学院(自然科学版), 2018, 31, 160.)

[2] Huang, G. B; Chen, Z. L.; Wei, X. S.; Chen, Y..; Li, X. Y.; Zhong, H.; Tan, M. X. Chin. J. Org. Chem. 2020, 40, 614 (in Chinese). (黄国保, 陈志林, 韦贤生, 陈钰, 李秀英, 仲辉, 谭明雄, 有机 化学, 2020, 40, 614.)

[3] Yang, Y.; Dou, D. D. Prog. Chem. 2014, 26, 706 (in Chinese). (杨勇，窦丹丹，化学进展, 2014, 26, 706.)

[4] Pei, Q.; Ding, A. X. Prog. Chem. 2019, 31, 258 (in Chinese). (裴强, 丁爱祥, 化学进展, 2019, 31, 258.)

[5] Jeffrey, G. A.; Maluszynska, H. Int. J. Biol. Macromol. 1982, 4, 173.

[6] Taylor, R.; Kennard, O.; Versichel, W. J. Am. Chem. Soc. 1984, 106, 244.

[7] Albrecht, G.; Corey, R. B. J. Am. Chem. Soc. 1939, 61, 1087.

[8] Jeffrey, G. A.; Mitra, J. J. Am. Chem. Soc. 1984, 106, 5546.

[9] Zhang, D. W.; Zhao, X.; Hou, J. L.; Li, Z, T. Chem. Rev. 2012, 112, 5271 .

[10] Zhang, D. W.; Li, Z. T. Chin. J. Org. Chem. 2012, 32, 2009 (in Chinese). (张丹维, 黎占亭, 有机化学, 2012, 32, 2009.)

[11] Hu, J. C.; Feng, W.; Li, X. H.; Yang, L. Q.; Yuan, L. H.; He, L.; Gong, B. Acta Phys.-Chim. Sin. 2010, 26, 1811 (in Chinese). (胡晋川, 冯文, 李向晖, 杨柳青, 袁立华, 何兰, 龚兵, 物理化 学学报, 2010, 26, 1811.)

[12] Yang, Y. A.; Feng, W.; Yuan, L. H. Chem. J. Chin. Univ. 2011, 32, 1950 (in Chinese).

(杨永安, 冯文, 袁立华, 高等学校化学学报, 2011, 32, 1950.)
[13] Yamato, K.; Kline, M.; Gong, B. Chem. Commun. 2012, 48, 12142.

[14] Gong, B.; Shao, Z. F. Acc. Chem. Res. 2013, 46, 2856.

[15] Si, W.; Xin, P. Y.; Li, Z. T.; Hou, J. L. Acc. Chem. Res. 2015, 48, 1612.

[16] Li, Z T. Prog. Chem. 2011, 23, 1.

[17] Zhang, D. W.; Zhao, X.; Li, Z. T. Acc. Chem. Res. 2014, 47, 1961.

[18] Liu, C. Z.; Yan, M.; Wang, H.; Zhang, D. W.; Li, Z. T. ACS Omega 2018, 3, 5165 .

[19] Gong, B. Acc. Chem. Res. 2012, 45, 2077.

[20] Zhu, J.; Parra, R. D.; Zeng, H. Q.; Skrzypczak-Jankun, E.; Zeng, X. C.; Gong, B. J. Am. Chem. Soc. 2000, 122, 4219.

[21] Parra, R. D.; Zeng, H. Q.; Zhu, J.; Zheng, C.; Zeng, X. C.; Gong, B. Chem.-Eur. J. 2001, 7, 4352.

[22] Parra, R. D.; Gong, B.; Zeng, X. C. J. Chem. Phys. 2001, 115, 6036.

[23] Wang, H.; Zhang, Y. K.; Zou, S.; Cao, J. X.; Huang, Q. F.; Wang, Q. W.; Zhu, J. Chin. J. Org. Chem. 2018, 38, 2060 (in Chinese). (王恒，张宇坤，邹胜，曹金金鍂，黄晴菲，王启卫，朱槿，有机化 学, 2018, 38, 2060.)

[24] Hu, Z. Q.; Chen, C. F. Chem. Commun. 2005, 41, 2445.

[25] Li, F.; Gan, Q.; Xue, L.; Wang, Z. M.; Jiang, H. Tetrahedron Lett. 2009, 50, 2367.

[26] Li, X.; Zhan, C. L.; Wang, Y. B.; Yao, J. N. Chem. Commun. 2008, 44, 2444.

[27] Zhu, H. H.; He, W. W.; Zhan, C. L.; Li, X.; Guan, Z. S.; Guo, F. Q.; Yao, J. N. Tetrahedron 2011, 67, 8458.

[28] Jiang, H.; Léger, J. M.; Guionneau, P.; Huc, I. Org. Lett. 2004, 6, 2985.

[29] Berni, E.; Dolain, C.; Kauffmann, B.; Léger, J. M.; Zhan, C. L.; Huc, I. J. Org. Chem. 2008, 73, 2687.

[30] Liu, S. G.; Li, Y. Z.; Zuo, J. L.; You, X. Z. Acta Crystallogr., Sect. E 2004, 60, o1527.

[31] Tang, H. Z.; Doerksen, R. J.; Jones, T. V.; Klein, M. L.; Tew, G. N. Chem. Biol. 2006, 13, 427.

[32] Choi, S.; Isaacs, A.; Clements, D.; Liu, D.; Kim, H.; Scott, R. W.; Winkler, J. D.; DeGrado, W. F. Proc. Natl. Acad. Sci. U. S. A. 2009, 106, 6968.

[33] Zhu, Y. Y.; Wu, J.; Li, C.; Zhu, J.; Hou, J. L.; Li, C. Z.; Jiang, X. K.; Li, Z. T. Cryst. Growth Des. 2007, 7, 1490.

[34] Gan, Q.; Bao, C. Y.; Kauffmann, B.; Grélard, A.; Xiang, J. F.; Liu, S. H.; Huc, I.; Jiang, H. Angew. Chem. Int. Ed. 2008, 47, 1715.

[35] Gan, Q.; Li, F.; Li, G. P.; Kauffmann, B.; Xiang, J. F.; Huc, I.; Jiang, H. Chem. Commun. 2010, 46, 297.

[36] Zhu, J.; Wang, X. Z.; Chen, Y. Q.; Jiang, X. K.; Chen, X. Z.; Li, Z. T. J. Org. Chem. 2004, 69, 6221.

[37] Ferguson, J. S.; Yamato, K.; Liu, R.; He, L.; Zeng, X. C.; Gong, B. Angew. Chem. Int. Ed. 2009, 48, 3150.

[38] Guo, R.; Zhang, L.; Wang, H.; Zhang, D. W.; Li, Z. T. Polym. Chem. 2015, 6, 2382.

[39] Hu, Z. Q.; Chen, C. F. Tetrahedron 2006, 62, 3446.

[40] Lu, Y. X.; Shi, Z. M.; Li, Z. T.; Guan, Z. B. Chem. Commun. 2010, 46, 9019.

[41] He, L.; An, Y.; Yuan, L. H.; Yamato, K.; Feng, W.; Gerlitz, O.; Zheng, C.; Gong, B. Chem. Commun. 2005, 41, 3788

[42] He, L.; An, Y.; Yuan, L. H.; Feng, W.; Li, M. F.; Zhang, D. C.; Yamato, K.; Zheng, C.; Zeng, X. C.; Gong, B. Proc. Natl. Acad. Sci. U. S. A. 2006, 103, 10850.

[43] Du, Z. Y.; Ren, C. L.; Ye, R. J.; Shen, J.; Maurizot, V.; Lu, Y. J.; Wang, J.; Zeng, H, Q. Chem. Commun. 2011, 47, 12488.

[44] Bao, C. Y.; Kauffmann, B.; Gan, Q.; Srinivas, K.; Jiang, H.; Huc, I. Angew. Chem. Int. Ed. 2008, 47, 4153

[45] Shi, Z. M.; Wu, C. F.; Zhou, T. Y.; Zhang, D. W.; Zhao, X.; Li, Z. T. Chem. Commun. 2013, 49, 2673. 
[46] Shang, J.; Gan, Q.; Dawson, S. J.; Rosu, F.; Jiang, H.; Ferrand, Y.; Huc, I. Org. Lett. 2014, 16, 4992.

[47] Koppireddi, S.; Liu, C. Z.; Wang, H.; Zhang, D. W.; Li, Z. T. CrystEngComm 2019, 21, 2626.

[48] Gong, B. Chem.-Eur. J. 2001, 7, 4336.

[49] Zhang, Y. F.; Yamato, K.; Zhong, K.; Zhu, J.; Deng, J. G.; Gong, B. Org. Lett. 2008, 10, 4339.

[50] Zhao, Y. Y.; Connor, A. L.; Sobiech, T. A.; Gong, B. Org. Lett. 2018, 20, 5486.

[51] Hou, J. L.; Shao, X. B.; Chen, G. J.; Zhou, Y. X.; Jiang, X. K.; Li, Z. T. J. Am. Chem. Soc. 2004, 126, 12386.

[52] Li, C.; Wang, G. T.; Yi, H. P.; Jiang, X. K.; Li, Z. T.; Wang, R. X. Org. Lett. 2007, 9, 1797.

[53] Berl, V.; Huc, I.; Khoury, R. G.; Krische, M. J.; Lehn, J. M. Nature 2000, 407, 720 .

[54] Shirude, P. S.; Gillies, E. R.; Ladame, S.; Godde, F.; Shin-ya, K.; Huc, I.; Balasubramanian, S. J. Am. Chem. Soc. 2007, 129, 11890.

[55] Zheng, L.; Zhan, Y. L.; Yu, C. Y.; Huang, F.; Wang, Y.; Jiang, H. Org. Lett. 2017, 19, 1482.

[56] Zheng, D.; Zheng, L.; Yu, C. Y.; Zhan, Y. L.; Wang, Y.; Jiang, H. Org. Lett. 2019, 21, 2555.

[57] Zheng, D.; Yu, C. Y.; Zheng, L.; Zhan, Y. L.; Jiang, H. Chin. Chem. Lett. 2020, 31, 673.

[58] Zhu, Y. Y.; Yi, H. P.; Li, C.; Jiang, X. K.; Li, Z. T. Cryst. Growth Des. 2008, 8, 1294.

[59] Zhu, Y. Y.; Jiang, L.; Li, Z. T. CrystEngComm 2009, 11, 235.

[60] Li, C.; Ren, S. F.; Hou, J. L.; Yi, H. P.; Zhu, S. Z.; Jiang, X. K.; Li, Z. T. Angew. Chem. Int. Ed. 2005, 44, 5725.

[61] Li, C.; Zhu, Y. Y.; Yi, H. P.; Li, C. Z.; Jiang, X. K.; Li, Z. T.; Yu, Y. H. Chem.-Eur. J. 2007, 13, 9990.

[62] Wang, L.; Xiao, Z. Y.; Hou, J. L.; Wang, G. T.; Jiang, X. K.; Li, Z. T. Tetrahedron 2009, 65, 10544.

[63] You, L. Y.; Chen, S. G.; Zhao, X.; Liu, Y.; Lan, W. X.; Zhang, Y.; Lu, H. J.; Cao, C. Y.; Li, Z. T. Angew. Chem., Int. Ed. 2012, 51, 1657.

[64] Liu, Y. H.; Zhang, L.; Xu, X. N.; Li, Z. M.; Zhang, D. W.; Zhao, X.; Li, Z. T. Org. Chem. Front. 2014, 1, 494.

[65] Shang, J.; Gallagher, N. M.; Bie, F. S.; Li, Q. L.; Che, Y. K.; Wang, Y.; Jiang, H. J. Org. Chem. 2014, 79, 5134.

[66] Yuan, L. H.; Feng, W.; Yamato, K.; Sanford, A. R.; Xu, D. G.; Guo, H.; Gong, B. J. Am. Chem. Soc. 2004, 126, 11120.

[67] Yang, Y. A.; Yuan, L. H.; Hu, J. C.; Zou, S. L.; Feng, W.; Gong, B. Acta Phys.-Chim. Sin. 2010, 26, 1557 (in Chinese). (杨永安, 袁立华, 胡晋川, 邹树良, 冯文, 龚兵, 物理化学学报, 2010, 26, 1557.)

[68] Yang, Y. A.; Feng, W.; Hu, J. C.; Zou, S. L.; Gao, R. Z.; Yamato, K.; Kline, M.; Cai, Z. H.; Gao, Y.; Wang, Y. B.; Li, Y. B.; Yang, Y. L.; Yuan, L. H.; Zeng, X. C.; Gong, B. J. Am. Chem. Soc. 2011, 133, 18590 .

[69] Kline, M. A.; Wei, X. X.; Horner, I. J.; Liu, R.; Chen, S.; Chen, S.; Yung, K. Y.; Yamato, K.; Cai, Z. H.; Bright, F. V.; Zeng, X. C.; Gong, B. Chem. Sci. 2015, 6, 152.

[70] Wu, X. X.; Liu, R.; Sathyamoorthy, B.; Yamato, K.; Liang, G. X.; Shen, L.; Ma, S. F.; Sukumaran, D. K.; Szyperski, T.; Fang, W. H.; He, L.; Chen, X. B.; Gong, B. J. Am. Chem. Soc. 2015, 137, 5879.

[71] Feng, W.; Yamato, K.; Yang, L. Q.; Ferguson, J. S.; Zhong, L. J.; Zou, S. L.; Yuan, L. H.; Zeng, X. C.; Gong, B. J. Am. Chem. Soc. 2009, 131, 2629.

[72] Wu, X. X., Liang, G. X., Ji, G., Fun, H. K., He, L., Gong, B. Chem. Commun. 2012, 48, 2228.

[73] Qin, B.; Chen, X. Y.; Fang, X.; Shu, Y. Y.; Yip, Y. K.; Yan, Y.; Pan, S. Y.; Ong, W. Q.; Ren, C. L.; Su, H. B.; Zeng, H. Q. Org. Lett.
2008, 10, 5127.

[74] Qin, B.; Sun, C.; Liu, Y.; Shen, J.; Ye, R. J.; Zhu, J.; Duan, X. F.; Zeng, H. Q. Org. Lett. 2011, 13, 2270.

[75] Xing, L.; Ziener, U.; Sutherland, T. C.; Cuccia, L. A. Chem. Commun. 2005, 41, 5751.

[76] Zhu, Y. Y.; Li, C.; Li, G. Y.; Jiang, X. K.; Li, Z. T. J. Org. Chem. 2008, 73, 1745.

[77] Ernst, J. T.; Becerril, J.; Park, H. S.; Yin, H.; Hamilton, A. D. Angew. Chem., Int. Ed. 2003, 42, 535.

[78] Wu, Z. Q.; Jiang, X. K.; Zhu, S. Z.; Li, Z. T. Org. Lett. 2004, 6, 229.

[79] Wu, J.; Fang, F.; Lu, W. Y.; Hou, J. L.; Li, C.; Wu, Z. Q.; Jiang, X. K.; Li, Z. T.; Yu, Y. H. J. Org. Chem. 2007, 72, 2897.

[80] Pei, Q.; Tang, Q.; Tan, Z. L.; Lu, Z. L.; He, L.; Gong, B. RSC Adv. 2017, 7, 22248.

[81] Shi, Y. D.; Tang, Q.; Jiang, Y. F.; Pei, Q.; Tan, H. W.; Lu, Z. L.; Gong, B. Chem. Commun. 2018, 54, 3719.

[82] Li, X. H.; Fang, Y. Y.; Deng, P. C.; Hu, J. C.; Li, T.; Feng, W.; Yuan, L. H. Org. Lett. 2011, 13, 4628.

[83] Li, X. H.; Jia, Y. M.; Ren, Y.; Wang, Y. J.; Hu, J. C.; Ma, T.; Feng, W.; Yuan, L. H. Org. Biomol. Chem. 2013, 11, 6975.

[84] Yang, Y.; Yang, Z. Y.; Yi, Y. P.; Xiang, J. F.; Chen, C. F.; Wan, L. J.; Shuai, Z. G. J. Org. Chem. 2007, 72, 4936.

[85] Lin, J. B.; Xu, X. N.; Jiang, X. K.; Li, Z. T. J. Org. Chem. 2008, 73, 9403.

[86] Zhu, Y. Y.; Wang, G. T.; Li, Z. T. Org. Biomol. Chem. 2009, 7, 3243.

[87] Wang, L.; Wang, G. T.; Zhao, X.; Jiang, X. K.; Li, Z. T. J. Org. Chem. 2011, 76, 3531.

[88] Dolain, C.; Zhan, C. L.; Léger, J. M.; Daniels, L.; Huc, I. J. Am. Chem. Soc. 2005, 127, 2400.

[89] Yi, H. P.; Wu, J.; Ding, K. L.; Jiang, X. K.; Li, Z. T. J. Org. Chem. 2007, 72, 870 .

[90] Zheng, L.; Zheng, D.; Wang, Y. R.; Yu, C. Y.; Zhang, K.; Jiang, H. Org. Biomol. Chem. 2019, 17, 9573

[91] Qin, B.; Ren, C. L.; Ye, R. J.; Sun, C.; Chiad, K.; Chen, X. Y.; Li, Z.; Xue, F.; Su, H. B.; Chass, G. A.; Zeng, H. Q. J. Am. Chem. Soc. 2010, 132, 9564.

[92] Hu, J. C.; Chen, L.; Ren, Y.; Deng, P. C.; Li, X. W.; Wang, Y. J.; Jia, Y. M.; Luo, J.; Yang, X. S.; Feng, W.; Yuan, L. H. Org. Lett. 2013, 15,4670 .

[93] Li, Y. B.; Liu, C. H.; Xie, Y. Z.; Li, X.; Fan, X. L.; Yuan, L. H.; Zeng, Q. D. Chem. Commun. 2013, 49, 9021.

[94] Hu, J. C.; Chen, L.; Shen, J.; Luo, J.; Deng, P. C.; Ren, Y.; Zeng, H. Q.; Feng, W.; Yuan, L. H. Chem. Commun. 2014, 50, 8024.

[95] Mao, L. J.; Pan, W.; Fu, Y. H.; Chen, L. X.; Xu, M.; Ren, Y.; Feng, W.; Yuan, L. H. Org. Lett. 2017, 19, 18.

[96] Yi. H. P.; Shao, X. B.; Hou, J. L.; Li, C.; Jiang, X. K.; Li, Z. T. New J. Chem. 2005, 29, 1213.

[97] Yi, H. P.; Li, C.; Hou, J. L.; Jiang, X. K.; Li, Z. T. Tetrahedron $\mathbf{2 0 0 5}, 61,7974$.

[98] Zheng, L.; Zhan, Y. L.; Ye, L.; Zheng, D.; Wang, Y.; Zhang, K.; Jiang, H. Chem.-Eur. J. 2019, 25, 14162.

[99] Helsel, A. J.; Brown, A. L.; Yamato, K.; Feng, W.; Yuan, L. H.; Clements, A. J.; Harding, S. V.; Szabo, G.; Shao, Z. F.; Gong, B. J. Am. Chem. Soc. 2008, 130, 15784.

[100] Wei, X. X.; Zhang, G. Q.; Shen, Y.; Zhong, Y. L.; Liu, R.; Yang, N.; Al-mkhaizim, F. Y.; Kline, M. A.; He, L.; Li, M. F.; Lu, Z. L.; Shao, Z. F.; Gong, B. J. Am. Chem. Soc. 2016, 138, 2749.

[101] Xin, P. Y.; Zhu, P. P.; Su, P.; Hou, J. L.; Li, Z. T. J. Am. Chem. Soc. 2014, 136, 13078.

[102] Xin, P. Y.; Zhang, L.; Su, P.; Hou, J. L.; Li, Z. T. Chem. Commun. 2015, 51, 4819. 
[103] Zhang, K. D.; Zhao, X.; Wang, G. T.; Liu, Y.; Zhang, Y.; Lu, H. J.; Jiang, X. K.; Li, Z. T. Angew. Chem., Int. Ed. 2011, 50, 9866.

[104] Zhang, K. D.; Zhao, X.; Wang, G. T.; Liu, Y.; Zhang, Y.; Lu, H. J.; Jiang, X. K.; Li, Z. T. Tetrahedron 2012, 68, 4517.

[105] Zhang, K. D.; Zhou, T. Y.; Zhao, X.; Jiang, X. K.; Li, Z. T. Langmuir 2012, 28, 14839.

[106] Gan, Q.; Ferrand, Y.; Bao, C. Y.; Kauffmann, B.; Grélard, A.; Jiang, H.; Huc, I. Science 2011, 331, 1172.

[107] Ferrand, Y.; Gan, Q.; Kauffmann, B.; Jiang, H.; Huc, I. Angew. Chem., Int. Ed. 2011, 50, 7572.

[108] Cai, W.; Wang, G. T.; Xu, Y. X.; Jiang, X. K.; Li, Z. T. J. Am. Chem. Soc. 2008, 130, 6936
[109] Cai, W.; Wang, G. T.; Du, P.; Wang, R. X.; Jiang, X. K.; Li, Z. T. J. Am. Chem. Soc. 2008, 130, 13450.

[110] You, L. Y.; Wang, G. T.; Jiang, X. K.; Li, Z. T. Tetrahedron 2009, 65, 9494.

[111] Wang, G. T.; Zhao, X.; Li, Z. T. Tetrahedron 2011, 67, 48.

[112] Ren, C. L.; Xu, S. Y.; Xu, J.; Chen, H. Y.; Zeng, H. Q. Org. Lett. 2011, 13, 3840 .

[113] Zou, S. L.; He, L. T.; Zhang, J.; He, Y. Z.; Yuan, L. H.; Wu, L. X.; Luo, J.; Wang, Y. H.; Feng, W. Org. Lett. 2012, 14, 3584.

[114] Li, X. W.; Li, B.; Chen, L.; Hu, J. C.; Wen, C. D. Y.; Zheng, Q. D.; Wu, L. X.; Zeng, H. Q.; Gong, B.; Yuan, L. H. Angew. Chem., Int. Ed. 2015, 54, 11147.

(Fan, Y.) 